\title{
Optical characterisation of suspended particles in the Mackenzie River plume (Canadian Arctic Ocean) and implications for ocean colour remote sensing
}

\author{
D. Doxaran ${ }^{1}$, J. Ehn ${ }^{1,2}$, S. Bélanger ${ }^{3}$, A. Matsuoka ${ }^{4}$, S. Hooker ${ }^{5}$, and M. Babin ${ }^{4}$ \\ ${ }^{1}$ Laboratoire d'Océanographie de Villefranche, UMR7093, CNRS-UPMC, France \\ ${ }^{2}$ Centre for Earth Observation Science, University of Manitoba, Manitoba, Canada \\ ${ }^{3}$ Université du Québec à Rimouski, Canada \\ ${ }^{4}$ Takuvik Joint International Laboratory, CNRS - Université Laval, Québec, Canada \\ ${ }^{5}$ NASA/GSFC/Code 616.2, Greenbelt, MD 20771, USA \\ Correspondence to: D. Doxaran (doxaran@obs-vlfr.fr)
}

Received: 31 March 2012 - Published in Biogeosciences Discuss.: 27 April 2012

Revised: 24 July 2012 - Accepted: 30 July 2012 - Published: 22 August 2012

\begin{abstract}
Climate change significantly impacts Arctic shelf regions in terms of air temperature, ultraviolet radiation, melting of sea ice, precipitation, thawing of permafrost and coastal erosion. Direct consequences have been observed on the increasing Arctic river flow and a large amount of organic carbon sequestered in soils at high latitudes since the last glacial maximum can be expected to be delivered to the Arctic Ocean during the coming decade. Monitoring the fluxes and fate of this terrigenous organic carbon is problematic in such sparsely populated regions unless remote sensing techniques can be developed and proved to be operational.

The main objective of this study is to develop an ocean colour algorithm to operationally monitor dynamics of suspended particulate matter (SPM) on the Mackenzie River continental shelf (Canadian Arctic Ocean) using satellite imagery. The water optical properties are documented across the study area and related to concentrations of SPM and particulate organic carbon (POC). Robust SPM and POC: SPM proxies are identified, such as the light backscattering and attenuation coefficients, and relationships are established between these optical and biogeochemical parameters. Following a semi-analytical approach, a regional SPM quantification relationship is obtained for the inversion of the water reflectance signal into SPM concentration. This relationship is reproduced based on independent field optical measurements. It is successfully applied to a selection of MODIS satellite data which allow estimating fluxes at the river mouth
\end{abstract}

and monitoring the extension and dynamics of the Mackenzie River surface plume in 2009, 2010 and 2011. Good agreement is obtained with field observations representative of the whole water column in the river delta zone where terrigenous SPM is mainly constrained (out of short periods of maximum river outflow). Most of the seaward export of SPM is observed to occur within the west side of the river mouth.

Future work will require the validation of the developed SPM regional algorithm based on match-ups with field measurements, then the routine application to ocean colour satellite data in order to better estimate the fluxes and fate of SPM and POC delivered by the Mackenzie River to the Arctic Ocean.

\section{Introduction}

The Arctic Ocean is strongly influenced by direct river inputs (freshwater, nutrients, terrigenous suspended and dissolved substances). Polar amplification of climate change significantly impacts the Arctic Ocean with repercussions on both the regional and global carbon cycles (www.acia.uaf.edu). The melting of ice and permafrost, increasing precipitation and hydrological processes at high latitudes are changing freshwater discharge and the amount of terrestrial organic and inorganic matter that is delivered to the ocean (Peterson et al., 2002; Frey and McClelland, 2009). The fate of the 
presumably highly refractory terrigenous particulate organic carbon $\left(\mathrm{POC}_{\text {ter }}\right)$, expected to be resistant to degradation in coastal waters until burial in marine sediments, is quite uncertain (Hedges et al., 1997; Schlunz and Schneider, 2000) and warrants careful monitoring in coming years.

The bulk of river discharge into the Arctic Ocean occurs during a relatively short (3-4 months) summer period. During the rest of the year river outflow is greatly reduced by the presence of land-fast ice at the river mouths (McClelland et al., 2012). Monitoring Arctic coastal environments is difficult and costly as they constitute remote sparsely populated areas affected by extreme meteorological conditions. Due to limited field observations of concentrations of terrigenous substances transported by rivers to estuarine zones, current estimates of fluxes delivered by rivers to the Arctic Ocean are associated with dramatic uncertainties which prevent operational monitoring (Schlunz and Schneider, 2000; Lefouest et al., 2011). Ocean colour remote sensing observations represent a great potential for monitoring the fluxes of coloured terrigenous substances delivered by rivers into the Arctic Ocean, i.e. it can be employed to quantify fluxes at monthly, yearly and multi-year temporal scales and detect significant variations induced by changes in Arctic river regimes and draining basins. Such monitoring requires a calibration of existing ocean colour algorithms to account for the specific inherent optical properties (IOPs) of the coloured suspended and dissolved matters detected within the river mouth and turbid plume areas.

The Malina oceanographic expedition was conducted in the Beaufort Sea (Canadian Arctic ocean) onboard the Canadian research ice-breaker CCGS Amundsen in August 2009 (Fig. 1). The overall goal of the Malina project is to understand how biodiversity and biogeochemical fluxes in the Arctic Ocean are controlled by light penetration and how they are affected by ongoing climate change in the Arctic. The objective of the present study is to develop an algorithm to quantify and monitor the concentrations of suspended particulate matter (SPM) in the Arctic coastal waters directly influenced by the discharge of the Mackenzie River (Canada) and to apply this algorithm to ocean colour satellite data.

The Mackenzie River on its own delivers more terrigenous SPM to the Arctic Ocean than all the other Arctic rivers combined (Rachold et al., 2004; O'Brien et al., 2006), and is the main source of $\mathrm{POC}_{\text {ter }}$ (Rachold et al., 2004). However, spatial and temporal variations in these fluxes remain poorly documented. Lack of regular measurements made at the mouth of the Mackenzie River prevents the operational monitoring of the solid (SPM and POC $_{\text {ter }}$ ) fluxes delivered by the river to the Arctic Ocean. Based on field data collected episodically more than ten years ago, Yunker et al. (1993) observed an approximately stable SPM content of POC $_{\text {ter }}$ at the river mouth $(1.4 \pm 0.2 \%)$ during spring and summer floods;

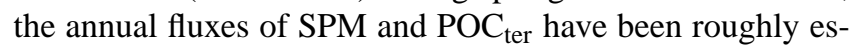
timated (Macdonald et al., 1998; O'Brien et al., 2006).
The first step in the present study is to document the content in organic carbon of SPM exported by the Mackenzie River in the Canadian Beaufort Sea, and then follow the spatial variations of this content along the river plume to the limits of its extension. Taking into account variations of particle composition, a second step is to determine the mass-specific IOPs of the SPM. The results obtained are used to establish a regional SPM quantification relationship for the MODIS ocean colour satellite sensor. This relationship is established using a semi-analytical then an empirical method, then applied to selected MODIS satellite data to remotely sense the dynamics of SPM within surface waters of the Mackenzie River plume. Satellite observations are complemented by field bio-optical measurements carried out in the delta zone to document the dynamics of SPM within the whole water column and estimate the monthly SPM and POC fluxes exported to the coastal Arctic Ocean.

\section{Data and methods}

\subsection{Study area}

The southeast of the Beaufort Sea is characterized by the presence of a large continental shelf occupying more than $60000 \mathrm{~km}^{2}$, bordered to the east by the Amundsen Gulf, to the west by the Mackenzie Canyon, to the south by the delta of the Mackenzie River, and by the Beaufort Sea and Canada Basin to the north (Fig. 1, Carmack and MacDonald, 2002). North of the Mackenzie Shelf, the circulation is highly variable and often linked to the seasonality of the outflow of the Mackenzie River which discharges $\sim 330 \mathrm{~km}^{3}$ of freshwater within a relatively short temporal window (34 months, with a peak at the end of June) (e.g. O'Brien et al., 2006). This discharge typically varies from about $4000 \mathrm{~m}^{3} \mathrm{~s}^{-1}$ during a long winter period (from December to May) to about $25000 \mathrm{~m}^{3} \mathrm{~s}^{-1}$ during summer (from June to August) (Fig. 1c).

At the end of winter, thermodynamically grown land-fast ice reaches a thickness of approximately $2 \mathrm{~m}$ and extends to the $20 \mathrm{~m}$ isobath. The external margin of the land-fast ice is subject to dynamic interactions with the Arctic pack ice, which results in the formation of a ridged ice barrier of considerable thickness (>20 m) (Macdonald et al., 1995). This zone of ice accumulation, known as the stamukhi zone, forms a barrier that traps fresh waters from the Mackenzie River. The river water accumulates behind the stamukhi zone during winter and forms what is essentially a lake (unofficially called Lake Herlinveaux) containing approximately $70 \mathrm{~km}^{3}$ of turbid freshwater (Carmack and Macdonald, 2002). Primary production under the land-fast ice is weak during this period due to light limitation caused by solar cycle, ice and intensive vertical mixing.

The spring ice break-up begins with the flooding of the Mackenzie River. By June, river flow is maximal and 

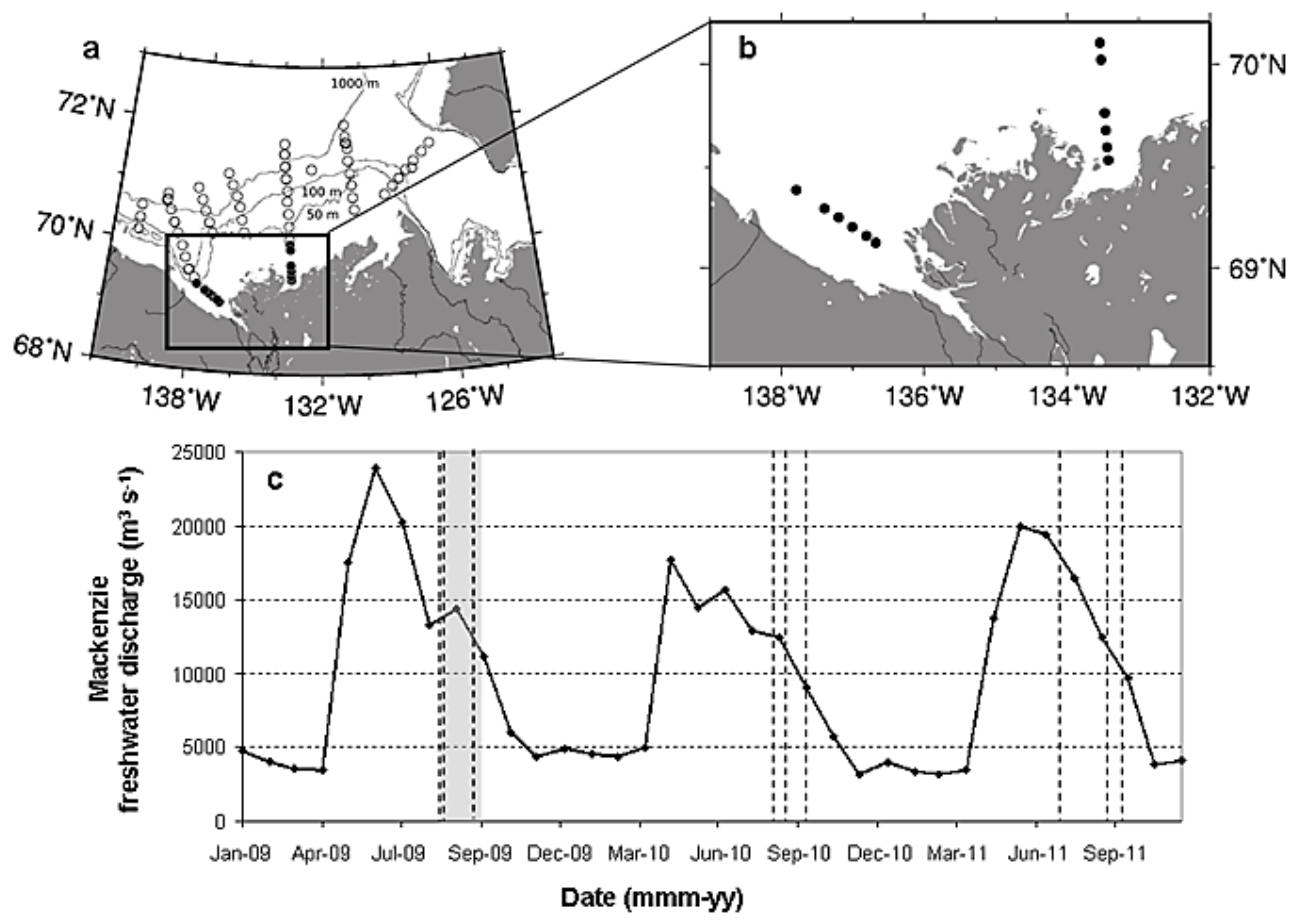

Fig. 1. Study area and sampling stations: whole study area (a) and river transects (b). Sampling stations (white points) and river transects stations (black points). Mackenzie River freshwater discharge in 2009, 2010 and 2011 (c) with the Malina field experiment period (in grey) and dates of the selected MODIS satellite images (dashed lines).

inundates the coastal zone until the stamukhi gives way under the pressure and melting generated by the warm mass of freshwater collecting upstream. Rapidly, the warm and very turbid plume can extend over an area of several thousand $\mathrm{km}^{2}$ (Macdonald et al., 1995).

During the summer, melting ice and continual inputs from the Mackenzie River form a 5 to $10 \mathrm{~m}$ layer of freshwater which occupies the shelf. It should be noted that it is not unusual to find ice above the continental shelf up until the end of July. In September, however, the shelf is typically completely free of ice (up to around $72^{\circ} \mathrm{N}$ ). The movement of the Mackenzie River freshwater plume depends principally on the wind conditions. Under calm or westerly winds, the Coriolis effect tends to maintain the freshwater stream along the coast in an eastward direction, while easterly winds transport the waters offshore towards the Canada Basin (e.g. Macdonald et al., 2002).

\subsection{Sampling strategy}

A network of sampling stations (Fig. 1) was set up to cover the Mackenzie River mouth, delta and continental shelf up to the limit of the Arctic pack ice extent. A total of 74 stations were sampled at least once: (i) using the CTD-rosette from the research ice-breaker; (ii) from a barge which was systematically deployed from the ship for bio-optical measurements; and (iii) from a Zodiac to collect water in the shallow waters along river transects. Only the barge and Zodiac were used along the river transects stations (Fig. 1b).

At each station, a standard frame comprising a CTD and optical sensors was deployed from the barge using a hand winch and a davit along vertical profiles from surface to $40 \mathrm{~m}$ depth (at $0.2 \mathrm{~m}$ per second). Temperature, pressure and salinity were measured using a Seabird Fastcat SBE-49. The optical sensors included: two absorption and attenuation meters (Wetlabs ac-9) equipped with 10 and $25 \mathrm{~cm}$ long tubes, two backscattering meters (Wetlabs ECO-BB3), one chlorophyll fluorescence sensor (Chelsea) and one CDOM fluorescence sensor (Wetlabs ECO-FL2). Light absorption and attenuation were measured at 14 wavelengths covering the visible and near-infrared spectral regions: 412, 440, 488, 510, 532, 555, 630, 676, 715, 730, 750, 767, 820 and $870 \mathrm{~nm}$. Light backscattering was measured at 6 wavelengths within a similar spectral range (440, 532, 650, 720, 770 and $870 \mathrm{~nm})$.

Apparent optical properties were measured using a Compact-Optical Profiling System (C-OPS) built by Biospherical Instruments Inc. (San Diego, California). The COPS system was equipped with an above-water global solar irradiance sensor $\left(E_{\mathrm{d}}\right)$ and two in-water downward irradiance and upwelling radiance $\left(E_{\mathrm{d}}\right.$ and $L_{\mathrm{u}}$, respectively) sensors. The three radiometers were equipped with the following common 18 optical wavebands: $320,340,380,395$, $412,443,465,490,510,532,555,560,625,665,670,683$, 710 , and $780 \mathrm{~nm}$. At each station, C-OPS data were recorded 
during at least three consecutive downcasts between the sea surface and a variable water depth corresponding to the $1 \%$ light level.

At the end of each cast, water samples were collected from selected depths using Niskin bottles mounted on the CTDrosette and from surface waters $(0.2 \mathrm{~m}$ depth) using a water sampling bottle from the barge and Zodiac. Water samples were kept stored in the cold and dark (up to two hours) until returning to the ship for immediate filtration and analyses.

\subsection{Biogeochemical measurements}

SPM concentration - known volumes $(V$, in 1$)$ of seawater $(0.2$ to 61 , depending on turbidity) were filtered in triplicate through pre-ashed $\left(1 \mathrm{~h}\right.$ at $\left.450{ }^{\circ} \mathrm{C}\right)$ and pre-weighed (mass $\mathrm{M0}$, in $\mathrm{mg}$ ) $25-\mathrm{mm}$ glass-fibre filters (Whatman, GF/F $0.7 \mu \mathrm{m}$ nominal pore size) at low vacuum (Van Der Linde, 1998). Each filter was then rinsed with Milli-Q water, dried for $12 \mathrm{~h}$ at $60^{\circ} \mathrm{C}$ and then stored at $-80^{\circ} \mathrm{C}$ in a clean Petri dish covered with aluminium foil. In the laboratory, filters were dried for $24 \mathrm{~h}$ at $60^{\circ} \mathrm{C}$, prior to weighing under a dry atmosphere (mass $M 1$, in $\mathrm{mg}$ ) to obtain the SPM concentration (in $\mathrm{g} \mathrm{m}^{-3}$ ) as

$\mathrm{SPM}=(M 1-M 0) / V$.

The average coefficient of variation of SPM for triplicates was $\pm 16 \%, 10 \%$ and $2 \%$, respectively, for SPM concentrations in the ranges $0.04-1,1-10$ and $10-100 \mathrm{~g} \mathrm{~m}^{-3}$. The relative uncertainty on measured SPM concentrations was therefore higher for minimum SPM concentrations, possibly due to (i) insufficient volume of water filtered, so that the increase in the filter mass $(M 1-M 0)$ was negligible; (ii) increased variability in spatial distributions of particulates in the clearest sampled waters. It was not practical to filter larger volumes of water as filtrations were done until near clogging of the filters. Thus, a reduction in uncertainty would require more replicate sampling, however, this was limited by the volume of water available and the number of filters prepared.

Particulate organic carbon (POC) concentrations were measured on the same GF/F filters used for SPM determination. The filters were acidified with $200-350 \mu \mathrm{HCl} 2 \mathrm{~N}$ to remove carbonates, dried at $60^{\circ} \mathrm{C}$ overnight and then burned on a pre-calibrated CHN analyzer (Perkin Elmer, 2400, combustion at $925^{\circ} \mathrm{C}$ ) for determination of the $\mathrm{CO}_{2}$ produced. The average coefficient of variation of POC for triplicates was $11 \%$, and it was $7 \%$ for the POC: SPM ratio.

\subsection{Optical measurements}

In this section we describe successively the measurements of the inherent optical properties (IOPs, measured in situ and in laboratory) and apparent optical properties (AOPs, namely the remote sensing reflectance, $R_{\mathrm{rs}}$ in $\mathrm{sr}^{-1}$, measured in the field).
CTD-IOP frame - the CTD, absorption, attenuation and fluorescence signals recorded using the instruments carried by the CTD-IOP frame were binned over 1-s periods, which is imposed by the instrument with the lowest acquisition rate, i.e. the ECO-BB3. A time lag of $0.5 \mathrm{~s}$ was imposed to measurements made on pumped water (CTD and ac-9). Taking into account the down and upward speed of the frame, a resulting minimum of 5 measurements was obtained every meter along the water column.

The ac- 9 sensors were regularly calibrated using pure (Milli-Q) water, i.e. before, during and after the Malina field campaign. The raw absorption and attenuation spectral values were corrected for temperature and salinity effects following the recommended procedure (Wetlabs ac-9 User's Guide, 2008) using correction coefficients provided by Sullivan et al. (2006) and Langford et al. (2001), respectively, in the visible and near-infrared spectral regions. The "proportional" method was then used to correct for residual scattering effects on absorption measurements (Zaneveld et al., 1994). Wavelength $870 \mathrm{~nm}$ was used as the reference wavelength where particulate absorption was assumed to be negligible.

The total volume scattering function measured at $117^{\circ}$ with the ECO-BB3 sensors, $\beta\left(117^{\circ}\right)$ in $\mathrm{m}^{-1} \mathrm{sr}^{-1}$, was first corrected for absorption losses along the scattered photon pathway (Wetlabs ECO BB User's Guide, 2007). Then, taking into account the measured water temperature, molecular scattering by water was calculated (Morel, 1974) and subtracted from the absorption-corrected values to retrieve the particulate scattering signal, $\beta \mathrm{p}\left(117^{\circ}\right)$. Finally, the particulate backscattering coefficient, $b_{\mathrm{bp}}(\lambda)$ in $\mathrm{m}^{-1}$, was determined through estimation of $\beta \mathrm{p}\left(117^{\circ}\right)$ using the $\chi$ factor proposed by Boss and Pegau (2001) based on measurements of the volume scattering function with high angular resolution in a diversity of water types. The different steps in the processing of the ECO-BB data are summarized as

$b_{\mathrm{bp}}(\lambda)=2 \pi \chi\left(\beta\left(117^{\circ}, \lambda, a\right) e^{0.0391 \mathrm{a}}-\beta_{\mathrm{w}}\left(117^{\circ}, \lambda\right)\right)$

where $\lambda$, in $\mathrm{nm}$, is the wavelength; $a$ in $\mathrm{m}^{-1}$, is the absorption coefficient measured with ac- 9 sensors at the corresponding wavelength; and $\chi$ has a fixed value of 1.1.

The particulate scattering coefficient, $b_{\mathrm{p}}$ in $\mathrm{m}^{-1}$, was simply obtained as the difference between the measured attenuation and absorption coefficients:

$b_{\mathrm{p}}(\lambda)=c(\lambda)-a(\lambda)$.

As a result, the vertical profiles of water temperature, salinity and fully-corrected multi-spectral optical properties (absorption, attenuation, particulate scattering and backscattering coefficients, CDOM and Chl $a$ fluorescence signals) were obtained at each station.

Laboratory measurements - water samples collected from the barge and Zodiac were transported to the ship for measurements of particulate absorption using the filter-pad technique. A known volume of sampled water was filtered 
through Whatmann GF/F glass-fibre filters. Each filter was then placed in the centre of a $150-\mathrm{mm}$ integrating sphere (Labsphere) equipped with a home-made filter-holder (see Röttgers and Gehnke (2012) for technical details). This method does not require near-infrared correction as scattering effects are negligible. The optical density $\left(\mathrm{OD}_{\mathrm{f}}\right)$ of particles retained on the filter was then measured using a PerkinElmer Lambda-19 spectrophotometer, from 300 to $800 \mathrm{~nm}$. $\mathrm{OD}_{\mathrm{f}}$ was converted into particulate absorption coefficient $\left(a_{\mathrm{p}}, \mathrm{m}^{-1}\right)$ using the following expression:

$a_{\mathrm{p}}=\frac{2.303}{\alpha} \times\left(\mathrm{OD}_{\mathrm{f}}-\mathrm{OD}_{\text {blank }}\right) \times \frac{A}{V}$

where $\mathrm{OD}_{\text {blank }}$ is the absorbance of a blank filter, $A$ the clearance area of the particles on the filter $\left(\mathrm{m}^{2}\right), V$ the volume filtered $\left(\mathrm{m}^{3}\right)$, and $\alpha$ a path length amplification factor. $\mathrm{OD}_{\text {blank }}$ was determined by averaging the absorbance spectra of 12 blank-filters measured during the course of the field campaign (e.g. $\mathrm{OD}_{\text {blank }}(550)=-0.005 \pm 0.002$ ). While $\alpha$ is within the range 2 to 2.5 when OD is determined using the common transmittance technique (Roesler, 1998); it reaches $\sim 4$ to $\sim 4.5$ when OD is determined using an integrating sphere (Röttgers and Gehnke, 2012). Röttgers and Gehnke (2012) observed a linear relationship between $\mathrm{OD}_{\mathrm{f}}$ and $a_{\mathrm{p}}$, with the condition $\mathrm{OD}_{\mathrm{f}}<0.1$ and recommended a value of 4.5 for $\alpha$; however, $\alpha$ tends to decrease when $\mathrm{OD}_{\mathrm{f}}$ increases beyond 0.1 (Röttgers and Gehnke, 2012). Since it was not always possible to keep $\mathrm{OD}_{\mathrm{f}}<0.1$ due to the large number of samples processed onboard, we adopt the following relationship between $\alpha$ and $\mathrm{OD}_{\mathrm{f}}$ derived from batch cultures (Röttgers, personal communication):

$\alpha=2.9 \mathrm{OD}_{\mathrm{f}}^{2}-4.76 \mathrm{OD}_{\mathrm{f}}+4.5$.

Pigments were then extracted within $24 \mathrm{~h}$, using methanol (Kishino et al., 1985), which essentially removes all pigments (95\% of sample). The filter was once again placed in the centre of the integrating sphere to measure the absorption coefficient of non-algal particles, $a_{\text {nap }}$ in $\mathrm{m}^{-1}$. The absorption coefficient of phytoplankton, $a_{\text {phy }}$ in $\mathrm{m}^{-1}$, was obtained by subtracting $a_{\text {nap }}$ from the total particulate absorption coefficient. For some exceptions, $a_{\text {nap }}$ data were fitted between 300-380, 521-640 and 700-750 nm to eliminate residue of pigment absorption (see Babin et al., 2003a). For a few samples, no $a_{\text {nap }}$ data were available and the $a_{\text {phy }}$ spectrum was obtained numerically following Bricaud and Stramski (1990).

The detailed methodology to determine the light absorption coefficient of CDOM is described in Matsuoka et al. (2012). Briefly, water samples from the barge and Zodiac were collected using cleaned plastic bucket or glassbottles and kept stored in the cold and dark until our return to the ship. Water samples were then immediately filtered using $0.2 \mu \mathrm{m}$ GHP filters (Acrodisc Inc.) to measure light absorbance by CDOM using a liquid waveguide system, UltraPath (World Precision Instruments, Inc.), from 200 to $735 \mathrm{~nm}$ at $1 \mathrm{~nm}$ increments. This instrument allows selection of the most appropriate optical path length ranging from 0.05 to $2 \mathrm{~m}$ (i.e. $0.05,0.1,0.5$ or $2 \mathrm{~m}$ ). In most cases, a $2 \mathrm{~m}$ optical path length was used for the measurement, except for coastal waters at the Mackenzie River mouth where a $0.1 \mathrm{~m}$ optical path length was used. The absorption coefficient of CDOM, $a_{\mathrm{CDOM}}$ in $\mathrm{m}^{-1}$, was then calculated (Matsuoka et al., 2012).

In situ AOP measurements - the $R_{\mathrm{rs}}$ signal is defined as the ratio between the water-leaving radiance, $L_{\mathrm{w}}$ in $\mathrm{W} \mathrm{m} \mathrm{m}^{-2} \mathrm{sr}^{-1} \mathrm{~nm}^{-1}$, and the global solar irradiance signal, $E_{\mathrm{d}}$ in $\mathrm{W} \mathrm{m}^{-2} \mathrm{~nm}^{-1}$, both just above the sea surface at $z=0^{+}$ (Mobley, 1994). At each station, the $L_{\mathrm{w}}$ and $E_{\mathrm{d}}$ signals were respectively derived and measured using a C-OPS. This instrument is based on a cluster of 19 state-of-the-art microradiometers spanning $320-780 \mathrm{~nm}$ and a new kite-shaped backplane design (Morrow et al., 2010) which includes tuneable ballast and buoyancy plus pitch and roll adjustments, to provide unprecedented stability and vertical resolution in near-surface waters. Data sets collected as part of the development activity to produce the first C-OPS instrument and the Malina expedition were of sufficient resolution and quality to show uncertainties in the execution of apparent optical properties; sampling protocols are measurable at the $1 \%$ and $1 \mathrm{~cm}$ level with C-OPS (Hooker et al., 2012).

During three consecutive C-OPS downcasts, the upwelling radiance was measured as function of water depth and extrapolated up to the water surface (at null depth $z=0^{-}$) over a near-surface interval with homogenous water properties (verified with temperature and attenuation parameters). The water-leaving radiance signal, $L_{\mathrm{w}}$, was obtained from $L_{\mathrm{u}}$ $\left(0^{-}\right)$as

$L_{\mathrm{W}}\left(\lambda, 0^{+}\right)=0.54 L_{\mathrm{u}}\left(\lambda, 0^{-}\right)$

where the constant 0.54 accurately accounts for the partial reflection and transmission of the upwelled radiance through the sea surface, as confirmed by Mobley (1999). A verification of the extrapolation process used to determine $L_{\mathrm{u}}(\lambda$, $0^{-}$) was provided by comparing the in-water determination of $E_{\mathrm{d}}\left(\lambda, 0^{-}\right)$to the above-water solar irradiance signal using

$E_{\mathrm{d}}\left(\lambda, 0^{-}\right)=0.97 E_{\mathrm{d}}\left(\lambda, 0^{+}\right)$

where the constant 0.97 represents the applicable air-sea transmittance, Fresnel reflectances, and the irradiance reflectance, and is determined to an accuracy better than $1 \%$ for solar elevations above $30^{\circ}$ and low-to-moderate wind speeds.

The appropriateness of the extrapolation interval was evaluated by determining if Eq. (7) was satisfied to within approximately the uncertainty of the calibrations (a few percent); if not, the extrapolation interval was redetermined while keeping the selected depths within a homogeneous layer until the disagreement was minimized (usually to within $5 \%$ ). 


\section{Results and discussion}

\subsection{Concentration and composition (organic carbon content) of suspended particles}

During the Malina field campaign, SPM concentrations within surface waters $(0-1 \mathrm{~m}$ depth) were observed to vary between 0.05 and $142 \mathrm{~g} \mathrm{~m}^{-3}$, with arithmetic and geometric mean values of 2.9 and $0.6 \mathrm{~g} \mathrm{~m}^{-3}$, respectively. Suspended particles from the river delta, river plume and from the Beaufort Sea away from direct influence of the river plume could be considered separately and were distinguished based on their SPM concentration range: $10-150 \mathrm{~g} \mathrm{~m}^{-3}, 1-10 \mathrm{~g} \mathrm{~m}^{-3}$ and $0.05-1 \mathrm{~g} \mathrm{~m}^{-3}$, respectively. The surface POC concentration was observed to vary between 0.01 and $2 \mathrm{~g} \mathrm{~m}^{-3}$, with arithmetic and geometric mean values of 0.11 and $0.05 \mathrm{~g} \mathrm{~m}^{-3}$, respectively.

Interestingly, linear relationships were found between the SPM and POC concentrations, in each of the water masses (delta, plume and open waters) (Fig. 2). A determination coefficient close to $1(N=5)$ and a slope of 0.0089 were found in the river delta (Fig. 2a), indicating a stable composition of suspended particles (a priori mineral-rich particles, average POC: SPM $=2.2 \%$ ). The robustness of this relationship could not be assessed in detail as only two river transects were conducted (west and east river mouths). In the river plume, the determination coefficient of the linear relationship is much lower $\left(R^{2}=0.51, N=12\right)$ indicating higher variations of the SPM composition in this transition zone between mineral-rich particles in turbid river waters and potentially organic-rich particles in open ocean waters (average POC: $\mathrm{SPM}=12.2 \%$ ). This last statement is confirmed by a high determination coefficient $\left(R^{2}=0.85, N=51\right.$, average POC: $\mathrm{SPM}=21 \%$ ) observed between the SPM and POC concentrations in open ocean waters (probably due to reduced variability in particle composition).

A major implication in terms of operational monitoring is that if surface SPM concentrations can be retrieved from either ocean colour remote sensing or field optical measurements over the study area, the corresponding POC concentration can be reasonably well estimated using the empirical linear relationships presented here (Fig. 2a). This statement remains valid when considering SPM which was sampled at various water depths from 0 to $150 \mathrm{~m}$, including the deep chlorophyll maximum (DCM) (Fig. 2b). Based on chlorophyll fluorescence data (not shown), there was no DCM in the very shallow waters of the delta zone. Along the continental shelf (water depths ranging from 20 to $200 \mathrm{~m}$ ) directly influenced by the river plume, a DCM was usually located at depths varying from 15 to $40 \mathrm{~m}$. It was systematically detected within 60 and $90 \mathrm{~m}$ depth in open ocean waters (data not shown). Compared with results obtained for surface waters, the relationship between SPM and POC within the water column: (i) is the same in the river delta (as only surface waters were sampled); or (ii) only slightly changes in the open
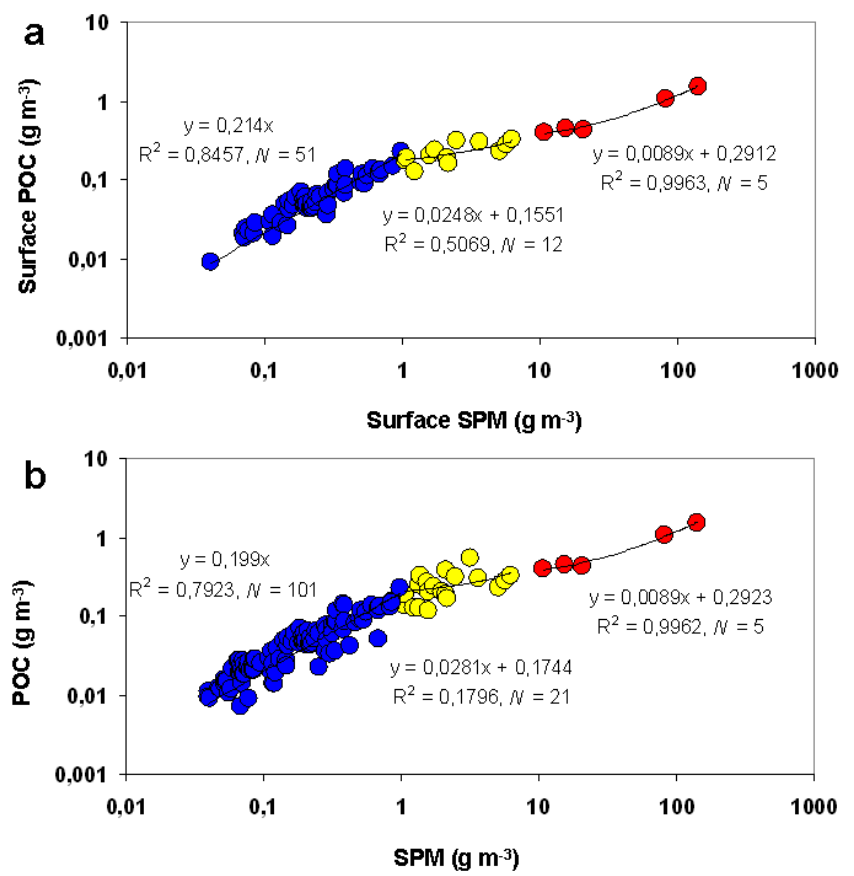

Fig. 2. Relationship between the POC and SPM concentrations in the Mackenzie continental shelf: (a) within surface waters $(0-4 \mathrm{~m}$ depth) and (b) within the water column (0-150 m depth). The following three ranges of SPM concentrations are distinguished: 0.02$1 \mathrm{~g} \mathrm{~m}^{-3}$ (blue); $1-10 \mathrm{~g} \mathrm{~m}^{-3}$ (yellow) and 10-200 $\mathrm{g} \mathrm{m}^{-3}$ (red).

ocean waters (slope of 0.20 instead of 0.21 ) with a slight decrease of the determination coefficient $R^{2}$ of $0.79(N=101)$ instead of $0.85(N=51)$. However, in the river plume waters, the linear relationship between SPM and POC becomes highly scattered ( $R^{2}$ of $\left.0.18, N=21\right)$; this is most probably due to the wide range of particles sampled in the river plume and oceanic waters below it (i.e. mineral-rich suspended sediments, organic-rich phytoplankton cells, aggregates of mineral and organic particles) corresponding to wide variations of the POC: SPM ratio from 2 to $25 \%$. This explains why there is no relationship between the measured POC and SPM concentrations.

A simple way to examine the variations of SPM composition in the study area is to use the POC:SPM ratio, expressed in $\%$. In open ocean waters, an average relationship has been observed relating the POC content of marine particles to their mean organic matter composition: $\mathrm{SPM}_{\mathrm{org}}: \mathrm{POC}=2.6$ (Copin-Montégut, 1980; Van Raaphorst and Melschaert, 1996; see also Babin et al., 2003b). In the case of organic-rich particles $\left(\mathrm{SPM} \approx \mathrm{SPM}_{\text {org }}\right)$, the inverse ratio POC : SPM would be equal to $38.5 \%$, i.e. $40 \pm 5 \%$. On the other hand, mineral-rich particles, such as suspended sediments delivered by rivers to the ocean, are expected to have a low POC: SPM ratio, e.g. between 1 and $2 \%$ in the case of the Mackenzie River (Yunker et al., 1993). 
In the Malina dataset (Fig. 3), suspended particles sampled in the river delta present a POC:SPM ratio of $2 \pm 1 \%$, with extreme values of 1 and $4 \%$, which is in close agreement with previous observations of Yunker et al. (1993). Inversely, in open ocean waters, the POC:SPM ratio presents strong variations from 15 to $40 \%$, indicating that some of the particulate samples in the Beaufort Sea were almost $100 \%$ organic. Again the river plume waters appear as a transition zone where the POC:SPM ratio varies from 5 to $16 \%$, i.e. from mineral-rich to organic-dominated particles. When considering SPM sampled at all waters depths, maximum POC : SPM ratios are observed (corresponding to almost entirely organic particles in the DCM).

\subsection{Characterisation of the inherent optical properties}

The inherent and apparent optical properties of surface waters in the Mackenzie continental shelf are analysed in order to establish proxies for the quantification of SPM from in situ and satellite remote sensing measurements. The inherent optical properties which directly impact on the ocean colour remote sensing signal $\left(R_{\mathrm{rS}}\right)$ are the absorption and backscattering coefficients (e.g. Gordon et al., 1975; Morel and Prieur, 1977). Inherent optical properties commonly used in field measurements for quantifying SPM concentration are the attenuation, and particulate scattering and backscattering coefficients. In this section, only measurements carried out along the river transects and in the most turbid stations of the river plume (SPM $>1 \mathrm{~g} \mathrm{~m}^{-3}$ ) are considered, as the objective of the study is to monitor the SPM dynamics in the river mouth and plume areas.

Firstly, consistency between absorption measurements made in situ with ac-9 sensors and in the laboratory with bench spectrophotometers is assessed. As the ac- 9 sensor is calibrated using pure water, the measured absorption signal is only representative of the CDOM plus SPM contributions. Absorption values measured within the first meter below the water surface (0-1 m depth) were averaged for direct comparison with laboratory absorption measurements on water samples collected at the same water depth. A satisfactory result was obtained when plotting the absorption coefficient from the ac-9 vs. the CDOM absorption coefficient (from the UltraPath) plus the total particulate absorption coefficient (from the spectrophotometer equipped with the integrating sphere). At 440, 555 and $715 \mathrm{~nm}$, linear relationships were obtained with slopes close to 1 (in the range 0.96 to 0.98 ), negligible intercepts and determination coefficients close to 1 $\left(R^{2}>0.96, N=16\right)$. A direct implication is that the total particulate absorption coefficient can be retrieved by subtracting the $a_{\text {CDOM }}$ signal (UltraPath) from the absorption coefficient measured with the ac-9 sensors.

As the total absorption coefficient is obtained from the inversion of the $R_{\mathrm{rs}}$ signal, i.e. from atmospherically corrected ocean colour satellite data, the next step was to identify spectral bands where the contribution of SPM is pre-

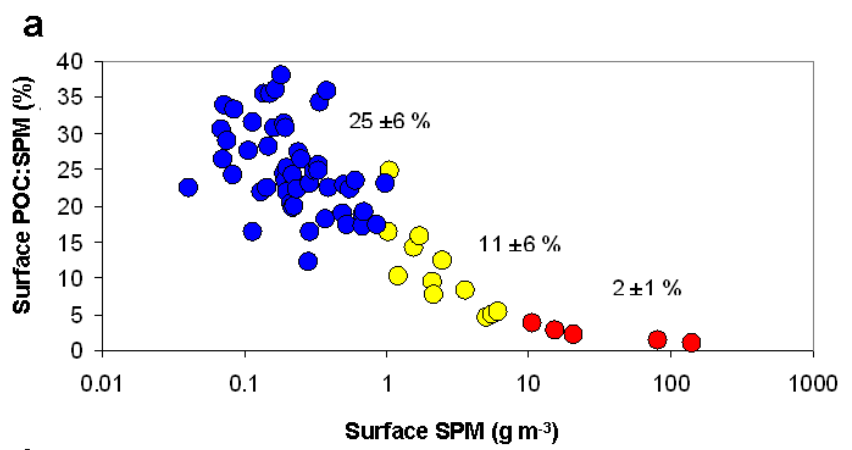

b

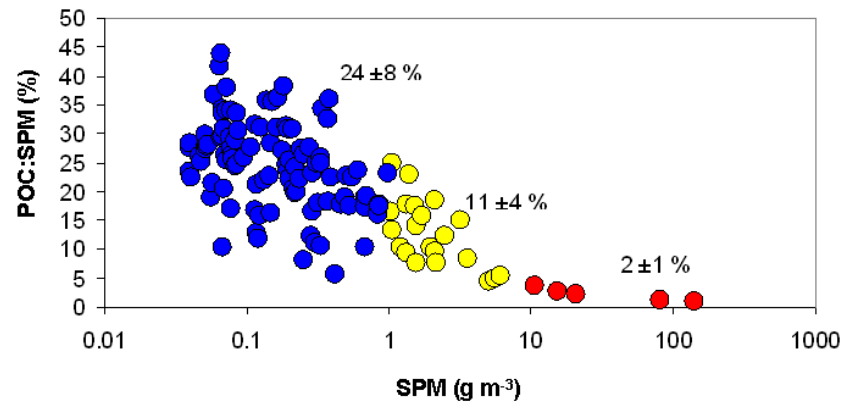

Fig. 3. Variations of the POC:SPM ratio (in \%) in the Mackenzie continental shelf as a function of the SPM concentration: (a) within surface waters (0-4 m depth) and (b) within the water column (0$150 \mathrm{~m}$ depth). The following three ranges of SPM concentrations are distinguished: $0.02-1 \mathrm{~g} \mathrm{~m}^{-3}$ (blue); $1-10 \mathrm{~g} \mathrm{~m}^{-3}$ (yellow) and $10-200 \mathrm{~g} \mathrm{~m}^{-3}$ (red).

dominant over that of CDOM. The inverse exercise (i.e. retrieving the CDOM absorption coefficient from the total absorption signal) was successfully achieved in the Mackenzie River plume by Bélanger et al. (2008). Except at the river mouth where the water optical properties were observed to be SPM-dominated, the CDOM contribution to total absorption proved to be predominant at short visible wavelengths $(<550 \mathrm{~nm})$ (Fig. 4a). Therefore, longer wavelengths should be preferably used to avoid a major influence of CDOM.

The respective contributions of phytoplankton pigments and non-algal particles to particulate absorption were then assessed using spectrophotometer measurements on particles retained on glass-fibre filters, before and after bleaching for depigmentation. The spectral variations of the ratio $a_{\text {nap }}: a_{\mathrm{p}}$ (Fig. $4 \mathrm{~b}$ ) show as expected that spectral bands centred around the Chl $a$ absorption peaks (440 and $675 \mathrm{~nm}$ ) should be avoided. The contribution of phytoplankton pigments is minimum $(<20 \%)$ in the near-infrared spectral region $(>700 \mathrm{~nm})$ but also within a visible spectral window $(530-650 \mathrm{~nm})$.

Taking into account the spectral contributions of CDOM and phytoplankton pigments to total absorption, wavebands in the near-infrared and in between 530 and $650 \mathrm{~nm}$ should be used to retrieve the SPM concentration in the Mackenzie River plume from $R_{\mathrm{rs}}$ measurements. 
a

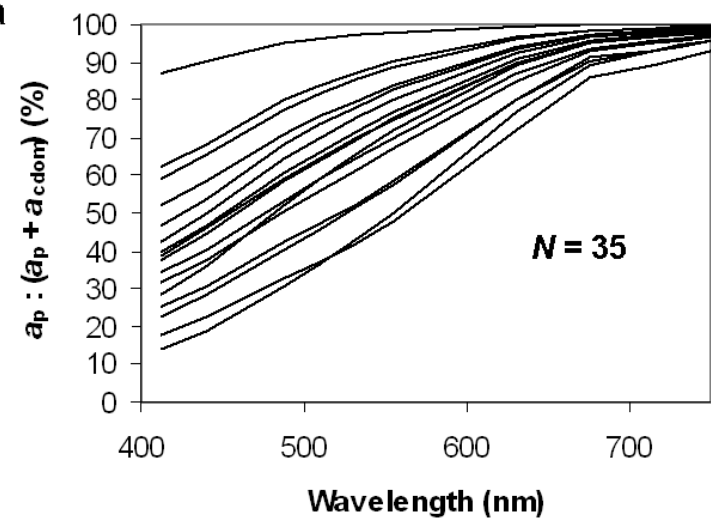

b

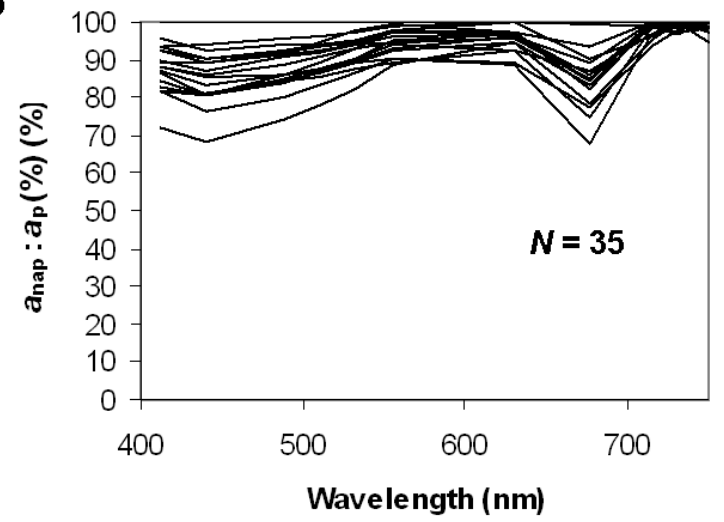

Fig. 4. Spectral contribution of particulate light absorption to particulate plus CDOM light absorption (a). Spectral contribution of light absorption by NAP to particulate light absorption (b). Results were obtained from CDOM and particulate light absorption measurements carried out in laboratory on surface waters sampled in the field (see the text for details).

To determine the SPM-specific absorption coefficient, $a_{\mathrm{p}}{ }^{*}$ in $\mathrm{m}^{2} \mathrm{~g}^{-1}$, the measured absorption signal from the ac-9 minus CDOM absorption, i.e. the difference $\left[a_{\mathrm{ac}} 9-a_{\mathrm{CDOM}}\right]$, was regressed as a function of SPM concentration. Linear relationships $\left(R^{2}>0.95, N=16\right.$, mean $\left.\mathrm{RMSE}=0.15 \mathrm{~m}^{-1}\right)$ were obtained at visible and near-infrared wavelengths (440, 555 and $715 \mathrm{~nm}$ ) which show that as a first approximation, a unique SPM-specific absorption coefficient can be derived which is representative of the most turbid waters in the Mackenzie River plume and delta. The mean $a_{\mathrm{p}}{ }^{*}$ (440) value obtained $\left(0.0611 \mathrm{~m}^{2} \mathrm{~g}^{-1}\right)$ is well in the range of previous values reported for mineral-rich suspended particles in coastal waters (Babin and Stramski, 2004; Estapa et al., 2012).

The next step, in the scope of quantifying SPM from field and remote sensing bio-optical measurements, was to relate the attenuation, particulate scattering and backscattering coefficients (respectively $c, b_{\mathrm{p}}$ and $b_{\mathrm{bp}}$, in $\mathrm{m}^{-1}$ ) to the SPM concentration.

A linear relationship is obtained between $c(555)$ and SPM $\left(R^{2}=0.97, N=35, \mathrm{RMSE}=0.77 \mathrm{~m}^{-1}\right)$, with a slope and de- termination coefficient both close to 1 , and a negligible intercept (Fig. 5a). This 1:1 relationship makes the beam attenuation coefficient at $555 \mathrm{~nm}$ an excellent proxy for the SPM concentration in the Mackenzie River plume. Note that results are only presented up to SPM concentrations of $20 \mathrm{~g} \mathrm{~m}^{-3}$, as the ac-9 sensors did saturate at the highest SPM concentrations encountered at the river mouth (west side). A linear relationship with null intercept and a determination coefficient close to 1 is obtained between $b_{\mathrm{p}}(555)$ and SPM (Fig. 5b) $\left(R^{2}=0.98, N=35\right.$, RMSE $\left.=0.61 \mathrm{~m}^{-1}\right)$; however, the slope $\left(0.88 \mathrm{~m}^{2} \mathrm{~g}^{-1}\right)$ is lower than that obtained for $c(555)$ indicating that at $555 \mathrm{~nm}$, light scattering by particles contributes to almost $90 \%$ of the total attenuation signal. These results are quite consistent with those reported by Babin et al. (2003b) and recently Neukermans et al. (2012) in Case 2 waters.

Finally, a third linear relationship is established between the particulate backscattering coefficient, $b_{\mathrm{bp}}$, and SPM, which is a fundamental relationship for the remote sensing of SPM in the Mackenzie River plume. This linear relationship is obtained at all the considered visible and near-infrared wavebands $\left(R^{2}>0.94, N=35\right)$, with the highest determination coefficient and lowest RMSE $\left(R^{2}=0.98\right.$, $N=35$, RMSE $=0.012 \mathrm{~m}^{-1}$ ) in the near-infrared spectral region, e.g. at $715 \mathrm{~nm}$ (Fig. 5c). Note that the value of the SPM-specific backscattering coefficient obtained at $715 \mathrm{~nm}$ $\left(0.0179 \mathrm{~m}^{2} \mathrm{~g}^{-1}\right.$, i.e. the slope of the linear regression established between $b_{\mathrm{bp}}(715)$ and SPM, Fig. 5c) is slightly higher than values reported by Neukermans et al. (2012) in the North Sea and French Guyana coastal waters, most probably as our dataset is mainly representative of the mineral-rich particles of the Mackenzie delta zone. The inverse linear relationship $\left(\mathrm{SPM}=54.7 \times b_{\mathrm{bp}}(715), R^{2}=0.98, N=35\right.$, mean RMSE $=1.05 \mathrm{~g} \mathrm{~m}^{-3}$ ) can be used to derive the SPM concentration from $b_{\mathrm{bp}}$ measurements.

Additionally, the particulate backscattering ratio, $b_{\mathrm{bp}}: b_{\mathrm{p}}$ in \%, is known to be to some extent representative of the SPM composition. This ratio is typically lower or equal to $1 \%$ in phytoplankton-dominated waters (Twardowski et al., 2001) and higher or equal to $2 \%$ in coastal waters (McKee et al., 2009) (see also Boss et al., 2004 for the theoretical foundation). The Malina dataset reveals that SPM in the Mackenzie River plume typically consists of mineral-rich particles specific of so-called Case 2 waters, with a $b_{\mathrm{bp}}: b_{\mathrm{p}}$ ratio at $715 \mathrm{~nm}$ of $2.2 \%$, which is the slope of the linear regression established between $b_{\mathrm{bp}}(715)$ and $b_{\mathrm{p}}(715)\left(R^{2}=1, N=35\right.$, RMSE $\left.=0.056 \mathrm{~m}^{-1}\right)($ Fig. $5 \mathrm{~d})$. This ratio significantly decreases to $1.5 \%$ in the clearest waters sampled offshore the river plume, i.e. for $b_{\mathrm{p}}(715)<0.05 \mathrm{~m}^{-1}(1.5 \%$ is the slope of the linear relationship, $R^{2}=0.68, N=13$, RMSE $=0.0005$ $\mathrm{m}^{-1}$ ) as SPM transitions from mineral-rich to phytoplankton dominated. 


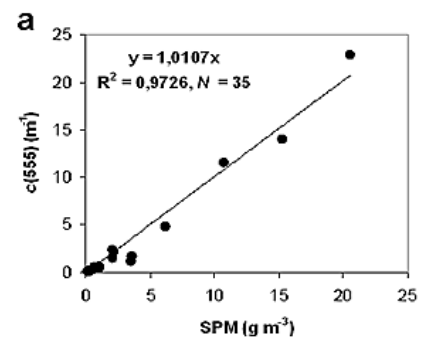

b

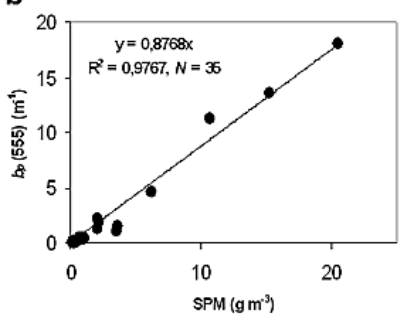

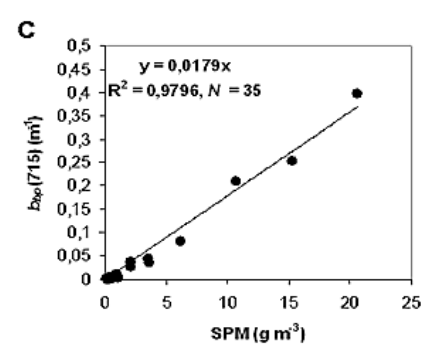

d

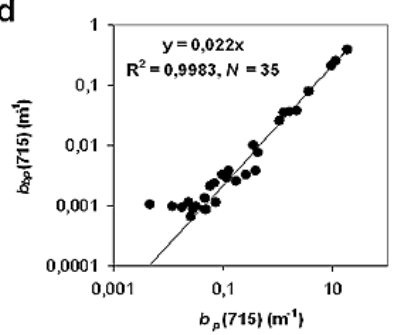

Fig. 5. Attenuation (a), particulate scattering (b) and backscattering (c) coefficients as a function of the SPM concentration. Results are presented at $555 \mathrm{~nm}$ (attenuation and scattering) and $715 \mathrm{~nm}$ (backscattering). Relationship between particulate light scattering and backscattering at $715 \mathrm{~nm}$ (d).

\subsection{Ocean colour SPM quantification algorithm}

Characterization of the inherent optical properties in waters directly influenced by the Mackenzie River plume has therefore allowed (i) establishment of direct bio-optical proxies for SPM concentration, namely the attenuation and backscattering coefficients; and (ii) identification of the most appropriate spectral bands for remotely sensing SPM using, e.g. MODIS or MERIS satellite data.

Taking into account the results obtained (Sect. 3.2), a semi-analytical approach is used to develop a robust SPM quantification relationship for the Mackenzie River plume. Following the approach developed by Doxaran et al. (2006), the spectral $R_{\mathrm{rs}}$ signal can be related to the SPM concentration according to

$R_{\mathrm{rS}}(\lambda)=\frac{0.176}{Q(\lambda)} \frac{b_{\mathrm{b}}(\lambda)}{a(\lambda)+b_{\mathrm{b}}(\lambda)}$

with $a$ and $b_{\mathrm{b}}$ the total absorption and backscattering coefficients (including the pure water contribution) and $Q$ the ratio of upwelling irradiance to upwelling radiance (to a first approximation, a constant Q-value of 3.6 sr was considered).

Note that there are currently no agreed look-up tables for the Q-factor in turbid coastal waters, but see the simulations made by Loisel and Morel (2001) and Park and Ruddick (2005). The Q-factors measured along river transects during the Malina field campaign, using a miniaturized multispectral $(406,438,494,510,560$ and $628 \mathrm{~nm})$ radiance camera (see Antoine et al., 2012 for measurement details), showed very limited spectral variations: maximum variations of $10 \%$ between 406 and $628 \mathrm{~nm}, 7 \%$ on average, at nadir. While

limited to the visible spectral domain, these measurements support the use of a spectrally-flat Q-factor in our model. Both $a$ and $b_{\mathrm{b}}$ coefficients are the sums of the contributions by the main optically active water constituents: pure seawater (w), CDOM and SPM (p) (which can be subdivided into $\mathrm{Chl} a$, for phytoplankton, and non-algal particles):

$a(\lambda)=a_{\mathrm{w}}(\lambda)+a_{\mathrm{CDOM}}(\lambda)+\mathrm{SPM} \times a_{\mathrm{p}}{ }^{*}(\lambda)$

$b_{\mathrm{b}}(\lambda)=b_{\mathrm{bw}}(\lambda)+\mathrm{SPM} \times b_{\mathrm{bp}}{ }^{*}(\lambda)$

where $a_{\mathrm{p}}{ }^{*}$ and $b_{\mathrm{bp}}{ }^{*}$ are respectively the SPM mass-specific absorption and backscattering coefficients, in $\mathrm{m}^{2} \mathrm{~g}^{-1}$.

In moderately turbid waters, visible wavebands have been considered in the scope of developing general relationships between the $R_{\mathrm{rs}}$ signal and SPM concentration, e.g. Stumpf and Pennock (1989) and more recently Nechad et al. (2010). In highly turbid sediment-dominated waters, robust SPM quantification relationships can be established using $R_{\mathrm{rs}}$ band ratios between the near-infrared (e.g. $\lambda_{\mathrm{NIR}}=800$ or $850 \mathrm{~nm}$ ) and visible (e.g. $\lambda_{\text {VIS }}=550$ or $650 \mathrm{~nm}$ ) spectral regions (Doxaran et al., 2002, 2003, 2006). Considering the nearinfrared spectral region is required in such waters where the $R_{\mathrm{rs}}$ signal tends to saturate at visible wavebands (Doxaran et al., 2002). As a first approximation, assuming limited spectral variations of bi-directional effects, such a ratio can be written as

$$
\begin{aligned}
& \frac{\operatorname{Rrs}\left(\lambda_{\mathrm{NIR}}\right)}{\operatorname{Rrs}\left(\lambda_{\mathrm{VIS}}\right)}=\frac{b_{\mathrm{bp}}\left(\lambda_{\mathrm{NIR}}\right)}{b_{\mathrm{bp}}\left(\lambda_{\mathrm{VIS}}\right)} \\
& \quad \times \frac{a_{\mathrm{w}}\left(\lambda_{\mathrm{VIS}}\right)+a_{\mathrm{CDOM}}\left(\lambda_{\mathrm{VIS}}\right)+\mathrm{SPM} \times\left[a_{\mathrm{p}}{ }^{*}+b_{\mathrm{bp}}{ }^{*}\right]\left(\lambda_{\mathrm{VIS}}\right)}{a_{\mathrm{w}}\left(\lambda_{\mathrm{NIR}}\right)+\mathrm{SPM} \times\left[a_{\mathrm{p}}{ }^{*}+b_{\mathrm{bp}}{ }^{*}\right]\left(\lambda_{\mathrm{NIR}}\right)}
\end{aligned}
$$

where light absorption by CDOM is assumed to be negligible in the near-infrared; the contribution by pure water to light backscattering is also negligible compared to that of SPM (for $\mathrm{SPM}>1 \mathrm{~g} \mathrm{~m}^{-3}$ ).

This simple model was run selecting 560 and $780 \mathrm{~nm}$, respectively, as visible and near-infrared wavelengths (as they match available C-OPS bands). The spectral pure water absorption coefficients are taken from Kou et al. (1993). The SPM-specific absorption and backscattering coefficients are set to the mean values documented in the present study: 0,0198 and $0,0031 \mathrm{~m}^{2} \mathrm{~g}^{-1}$ for the mass-specific absorption coefficients at 560 and $780 \mathrm{~nm} ; 0.0187$ and $0.0175 \mathrm{~m}^{2} \mathrm{~g}^{-1}$ for the mass-specific backscattering coefficients at 560 and $780 \mathrm{~nm}$. The contribution of CDOM to light absorption is determined based on results reported in Fig. 4a: $\left[a_{\mathrm{p}}+\right.$ $\left.a_{\mathrm{CDOM}}\right](560)=1.30 \times a_{\mathrm{p}}(560)$ and $\left[a_{\mathrm{p}}+a_{\mathrm{CDOM}}\right](780)=$ $1.05 \times a_{\mathrm{p}}(780)$. Using these values as inputs in the semianalytical model Eq. (11), the resulting relationship obtained between $R_{\mathrm{rs}}(780): R_{\mathrm{rs}}(560)$ and the SPM concentration (Fig. 6a) is of the same type as those obtained in several European sediment-dominated estuaries, namely the Gironde, Loire and Tamar (Doxaran et al., 2006).

An empirical SPM quantification relationship is obtained by regressing the $R_{\mathrm{rs}}(780): R_{\mathrm{rs}}(560)$ values measured using 

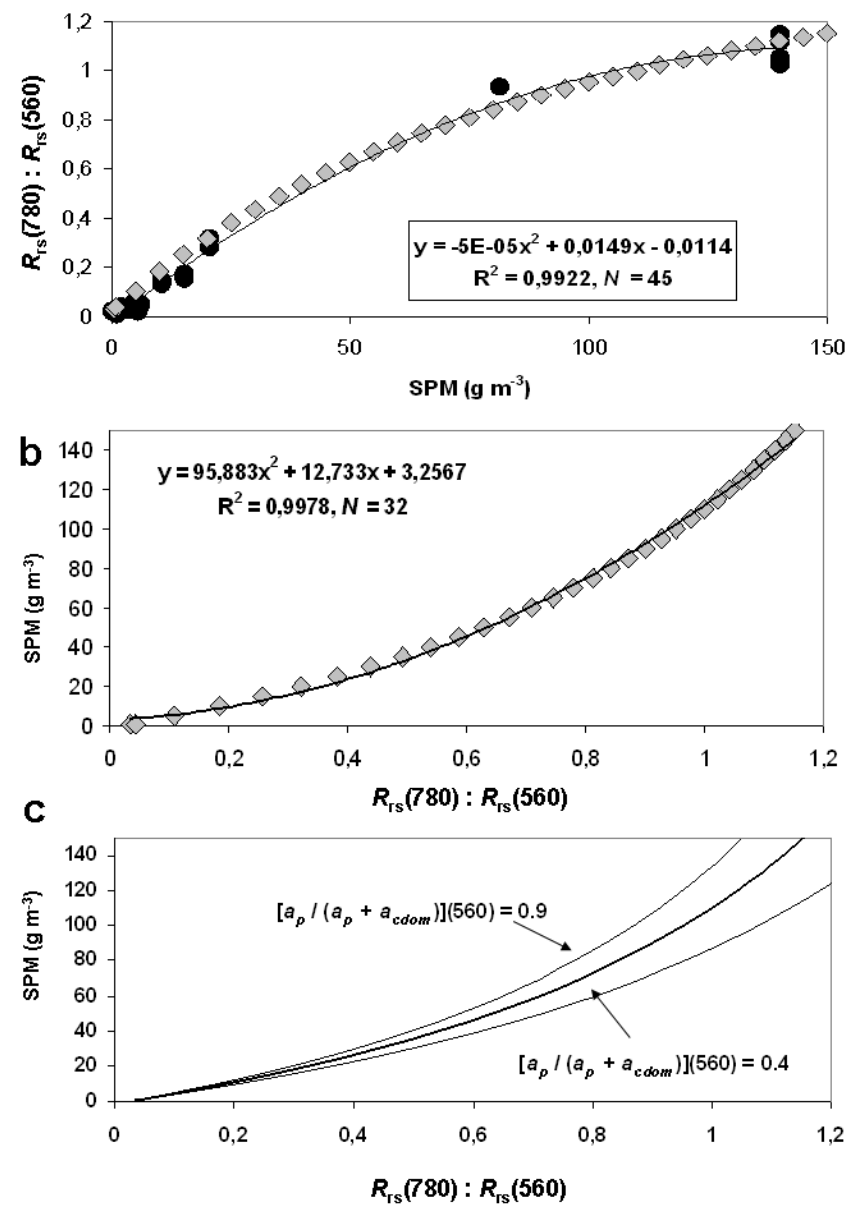

Fig. 6. Relationship between the $R_{\mathrm{rs}}(780): R_{\mathrm{rs}}(560)$ ratio and SPM concentration along the two river transects. (a) Empirical relationship (black points) with the associated best second order polynomial fit and semi-analytical relationship (grey points). (b) Inverse relationship giving the SPM concentration from the $R_{\mathrm{rs}}(780): R_{\mathrm{rs}}(560)$ ratio. (c) Potential influence of variations in CDOM contribution to light absorption at $560 \mathrm{~nm}$ on the established SPM quantification relationship (grey lines).

the C-OPS system as a function of measured SPM concentrations. A second order polynomial equation fits this empirical relationship over the whole range of SPM observed in situ $\left(0.1-150 \mathrm{~g} \mathrm{~m}^{-3}\right)$ and closely reproduces the semi-analytical relationship established using the mean SPM-specific inherent optical properties (Fig. 6a). Note that the semi-analytical model tends to overestimate the lowest SPM concentrations $\left(\leq 1 \mathrm{~g} \mathrm{~m}^{-3}\right)$ where some of the assumptions made in Eq. (9)-(11) are no longer valid. In order to compare these empirical and semi-analytical relationships, the measured $R_{\mathrm{rs}}(780): R_{\mathrm{rs}}(560)$ values were used as inputs in Eq. (11) to compute SPM concentrations. The statistics of the linear regression established between the measured and computed SPM concentrations $\left(R^{2}=0.98, N=45\right.$, slope $=0.94$, mean RMSE $=6.1 \mathrm{~g} \mathrm{~m}^{-3}$ ) shows the overall good performance of the semi-analytical model which only slightly underestimates the field-measured SPM (considered here as groundtruth). The averaged absolute differences observed between the computed and measured SPM concentrations (46\% (all data), $18 \%\left(\mathrm{SPM} \geq 5 \mathrm{~g} \mathrm{~m}^{-3}\right)$ and $\left.7 \%\left(\mathrm{SPM} \geq 10 \mathrm{~g} \mathrm{~m}^{-3}\right)\right)$ confirm the good performance of the semi-analytical model at least in the turbid waters of the Mackenzie River plume associated to high SPM concentrations. The inverse relationship allows retrieval of the surface SPM concentration in the Mackenzie River mouth and turbid plume from $R_{\mathrm{rs}}$ measurements around 560 and $780 \mathrm{~nm}$ (Fig. 6b).

We further examine the sensitivity of the mean semianalytical relationship to the variations in the SPM-specific IOPs and the CDOM contribution to total absorption. The sensitivity of the $R_{\mathrm{rs}}(780): R_{\mathrm{rs}}(560)$ ratio to variations in (i) $a_{\mathrm{p}}{ }^{*}$, (ii) $b_{\mathrm{bp}}{ }^{*}$ and (iii) CDOM contribution to light absorption by CDOM plus SPM was investigated using the semianalytical model Eq. (11). Based on the IOPs and SPM concentrations measured in the field, $a_{\mathrm{p}}{ }^{*}$ and $b_{\mathrm{bp}}{ }^{*}$ were observed to vary within $\pm 25 \%$ and $\pm 15 \%$, respectively, around their mean values at 560 and $780 \mathrm{~nm}$. The CDOM contribution to light absorption by CDOM plus SPM was observed to vary from $10 \%$ to $50 \%$ at $560 \mathrm{~nm}$, and from $1 \%$ to $5 \%$ at $780 \mathrm{~nm}$. These natural changes in $a_{\mathrm{p}}{ }^{*}$ and $b_{\mathrm{bp}}{ }^{*}$ have rather limited impacts on the computed $R_{\mathrm{rs}}(780): R_{\mathrm{rs}}(560)$ ratio (variations of $10 \%$ and $15 \%$, respectively). Changes in the CDOM contribution to light absorption by CDOM plus SPM have a higher impact (25\% variations in the $R_{\mathrm{rs}}(780): R_{\mathrm{rs}}(560)$ ratio). Using the established quantification relationship between $R_{\mathrm{rs}}(780): R_{\mathrm{rs}}(560)$ and SPM, a changing contribution of light absorption by CDOM is therefore the main factor inducing uncertainties in the estimated SPM concentration. Based on results reported on Figure $4 \mathrm{a}$, the ratio $\left[\left(a_{\mathrm{p}}+a_{\mathrm{CDOM}}\right) / a_{\mathrm{CDOM}}\right]$ at $560 \mathrm{~nm}$ varies from 1.10 to 1.60 around the mean value initially set at 1.30 . Taking into account these variations of the CDOM contribution to absorption, the extreme relationships used to retrieve the SPM concentration from the $R_{\mathrm{rs}}(780): R_{\mathrm{rs}}(560)$ ratio can be computed (Fig. 6c), which provide a first estimation of the uncertainties associated with the recovered SPM concentration.

\subsection{Remote sensing of SPM dynamics in the Mackenzie River plume}

The next step is to apply the empirical SPM quantification relationship to ocean colour images. MODIS-Aqua satellite data were selected in this study because of their (i) temporal resolution (at least one image recorded every day, depending on cloud cover), (ii) spectral resolution (providing one waveband at $555 \mathrm{~nm}$ and one at $748 \mathrm{~nm}$, i.e. close to those required: 560 and $780 \mathrm{~nm}$ ) and (iii) availability of several bands in the near-infrared and short-wave infrared spectral regions, which are useful for atmospheric corrections over turbid coastal waters (Wang and Shi, 2007). 
MODIS-scenes were selected in 2009, 2010 and 2011 to provide a synoptic view of the seasonal to multi-annual dynamics of SPM in the Mackenzie River plume. The selected dates are: 26 July, 31 July and 21 August 2009 (the 2009 summer period when the Malina campaign took place was associated with high cloud coverage); 4 August, 17 August and 7 September 2010; 28 June, 26 August and 12 September 2011. Two multi-scattering atmospheric corrections methods were tested on the selected MODIS data: (i) the nearinfrared correction (two bands) suitable for the case of moderately turbid waters and (ii) the near-infrared/shortwaveinfrared switching method better adapted to highly turbid waters (Wang and Shi, 2007). The first correction proved to be suitable for the majority of the turbid waters of the Mackenzie River plume with only the most turbid waters located at the river mouth being sometimes flagged. The second correction produced very similar results as the switch to shortwaveinfrared wavelengths was only required for a few pixels corresponding to the most turbid waters at the river mouth. The two correction methods were assumed to provide satisfactory results in the turbid waters of the Mackenzie River plume as they allowed retrieving similar $R_{\mathrm{rs}}$ values and spectral variations $(500-800 \mathrm{~nm})$ within the range observed in situ based on C-OPS measurements (Hooker et al., 2012). The first correction method was thus selected to retrieve the $R_{\mathrm{rs}}$ signal at 555 and $748 \mathrm{~nm}$, compute the $R_{\mathrm{rs}}(780): R_{\mathrm{rs}}(560)$ ratio and finally apply the established SPM quantification relationship (Fig. 6b). Clouds and sea-ice were systematically flagged. Results proved to be satisfactory in terms of retrieved ranges of $R_{\mathrm{rS}}(780): R_{\mathrm{rs}}(560)$ values and SPM concentrations (Fig. 7).

Only the summer period (June-September) is suitable for ocean colour satellite observations of the Mackenzie River plume due to limits imposed by solar light availability and sea-ice cover. However, this short period represents most of the variability observed in the region, such as the breakingup of the stamukhi (natural ice barrier at the river mouth), development and offshore extension of the Mackenzie turbid waters over the continental shelf and the progressive settling of the SPM on the shelf, which depends mainly on wind, tides, sea-ice and regional circulation conditions.

Very few cloud-free images were recorded coincidently with the Malina field experiment, i.e. between June and August 2009 (Fig. 1c). SPM maps derived from MODIS-Aqua data at the end of July show high SPM concentrations (from 10 to $50 \mathrm{~g} \mathrm{~m}^{-3}$ ) extending $200 \mathrm{~km}$ offshore from the river mouth (Fig. 7). SPM tended to be transported westwards, following the bottom morphology to the Mackenzie Canyon. One month later, at the end of August, the extension of the plume was more limited and SPM was clearly concentrated around the river mouth, resulting in the development of a maximum turbidity zone along the west side of the delta. The progressive decrease of freshwater river discharge in June $\left(23900 \mathrm{~m}^{3} \mathrm{~s}^{-1}\right)$, July $\left(20200 \mathrm{~m}^{3} \mathrm{~s}^{-1}\right)$, and then August to September (13300 and $14400 \mathrm{~m}^{3} \mathrm{~s}^{-1}$, respectively, see

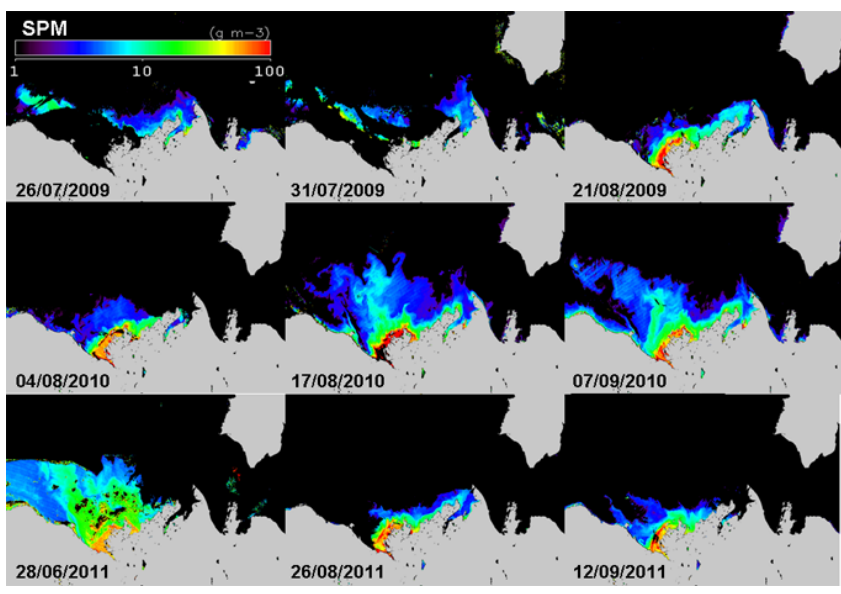

Fig. 7. Maps of SPM concentrations retrieved from selected MODIS-Aqua satellite data recorded in 2009 (top), 2010 (middle) and 2011 (bottom).

Fig. 1c) is consistent with the observed variation of SPM concentrations.

On the 4 August 2010, high SPM concentrations were located at a maximum turbidity zone in the river delta, as in August 2009. Thirteen days later (17 August 2010), the river plume was extending north with SPM concentrations higher than $10 \mathrm{~g} \mathrm{~m}^{-3}$ observed $250 \mathrm{~km}$ offshore (Fig. 7). A similar plume extension could be observed three weeks later (7 September 2010) but now with slightly lower SPM concentrations and a plume extending $200 \mathrm{~km}$ offshore (instead of $250 \mathrm{~km}$ mid-August).

In 2011, one cloud-free image offered a view of the extension of the river plume at the end of June (Figs. 1c and 7). At this time the offshore extension was the largest observed and corresponded to the highest surface SPM concentrations retrieved along the continental shelf, mainly along a channel from the west river mouth to the Mackenzie Canyon. This situation most probably resulted from the recent breaking of the stamukhi. The next available cloud-free images, measured at the end of August and beginning of September after a progressive decrease of the river outflow, showed the typical situation of a concentrated maximum turbidity zone surrounding the river mouth and only extending over the river delta.

Due to the absence of match-ups between satellite and field measurements in 2009, the SPM quantification algorithm developed here and applied to MODIS data could not be fully validated. However, a good correlation was obtained between the SPM quantification relationships established using the semi-analytical then empirical approaches. It is potentially affected by variations of CDOM concentrations which significantly impact on light absorption at $555 \mathrm{~nm}$ and induce uncertainties on satellite-derived SPM concentrations. Nonetheless, concentrations retrieved from MODIS data proved to be consistent with field observations. 


\subsection{Vertical dynamics of SPM in the Mackenzie River delta}

Ocean colour satellite data proved to provide useful information about the extension and dynamics of the Mackenzie River plume, through the estimation of surface SPM concentrations. However, remote sensing observations also present two major limits in the scope of studying SPM dynamics in a river plume. Firstly, they are limited to surface waters, i.e. the layer below the air-water interface where the solar light penetrates and is reflected towards satellite sensors. Depending on water turbidity and on the wavelength considered, this layer can be of depth less than $1 \mathrm{~m}$ and therefore no information is obtained concerning the vertical variations of SPM within the water column. Secondly, such passive radiometric measurements are dependent on the level of cloud coverage, which may prevent observations from being collected during key periods associated with the export of particles from rivers to the ocean (e.g. the summer 2009 period over the Mackenzie continental shelf). Field observations are therefore necessary to provide regular measurements within the whole water column, e.g. to detect bottom and intermediate nepheloid layers.

The Malina dataset was used specifically to document the vertical distribution of SPM in the Mackenzie River delta apparently associated with a permanent maximum turbidity zone. CTD and bio-optical measurements were carried out along river transects on 13 August 2009 (west side) and 16 August 2009 (east side), at a distance greater than $50 \mathrm{~km}$ offshore from the river mouth (salinity of 0 , water depths of $2 \mathrm{~m}$ (west), and $8 \mathrm{~m}$ (east)). For both transects, the $b_{\mathrm{bp}}(715)$ coefficient was used as a proxy for the SPM concentration. The water mass was well mixed and almost homogeneous in terms of temperature and salinity at the river mouth, while the stratification between fresh and salted waters started $5 \mathrm{~km}$ offshore (Figs. 8 and 9).

The most turbid waters were located in shallow regions of the western river mouth where predominantly freshwaters (salinity < 10) extend up to $20 \mathrm{~km}$ offshore (Fig. 8). This area is characterized by almost homogeneous vertical profiles of SPM, at least along a $10 \mathrm{~km}$ distance. From 10 to $35 \mathrm{~km}$ offshore from the mouth, fresh and saline water masses were stratified and two turbidity layers clearly formed: a $4 \mathrm{~m}$ thick surface layer and a thinner but more turbid bottom layer probably associated with different kinds of SPM (fine particles at the surface and coarse aggregates close to the bottom). This assumption is confirmed by the measured vertical variations of the particulate backscattering ratio, $b_{\mathrm{bp}}: b_{\mathrm{p}}$, at 532 and $715 \mathrm{~nm}$. In the delta zone, this ratio typically increases from $2 \%$ within surface waters to $3.5 \%$ within the bottom nepheloid layer. In deeper waters $(15$ to $40 \mathrm{~m}$ water depth), this ratio typically increases from $0.5-1.5 \%$ within surface waters to $2 \%$ close to the bottom. These variations reflect the presence of different types of particles along the water column: (i) mixed phytoplankton and mineral-rich par- ticles in the surface layer and (ii) suspended sediments in the bottom layer. The maximum turbidity zone was strictly confined within the river delta up to the $10 \mathrm{~m}$ isobath. Offshore, the water mass remained slightly stratified, both in terms of salinity and SPM, with significantly lower SPM concentrations $\left(<5 \mathrm{~g} \mathrm{~m}^{-3}\right)$.

Along the east river transect (Fig. 9), the freshwater influence was less pronounced (with minimum water salinity of 10) and SPM concentrations were approximately half those observed on the west side of the mouth. In terms of vertical profiles of turbidity and salinity, the water mass was rather homogeneous at the river mouth then progressively stratified to highly stratified from the river mouth to $50 \mathrm{~km}$ offshore (10 $\mathrm{m}$ isobath). With increasing distance from the mouth, the surface plume progressively declined, while the bottom layer became thicker with higher SPM concentrations, most probably resulting from flocculation processes which enhanced SPM settling. This assumption is supported by the observed variation trend in the shape of the attenuation coefficient spectrum $\left(c(\lambda)=A \lambda^{-\gamma}\right.$, with $\gamma$ the spectral slope): $\gamma$ typically decreases from 1.5 within surface waters to 0.8 in the bottom layer (not shown). These variations are representative of changes in the particle size distribution along the water column, with an increasing proportion of coarse particles occurring for decreasing $\gamma$-values (Boss et al., 2001).

The flocculation and settling of fine particles exported by the Mackenzie River onto the shelf seems to occur for water salinity varying from 0 to 4 : the SPM concentration measured within surface waters was observed to decrease by a factor of 7 from the river mouth (west side) to adjacent coastal waters with salinity of 4 , i.e. along a distance of $30 \mathrm{~km}$ (Fig. 10a). As a first approximation $\left(R^{2}=0.83, N=10\right)$, a power-law function can be used to model the decrease in SPM concentration with increasing water salinity. These results suggest that settling of SPM (which is enhanced by flocculation) occurs very rapidly close to the river mouth (typically within a $10-\mathrm{km}$ offshore distance) mainly at very low salinity $(0-1)$. Therefore, most of the SPM exported at the river mouth settle down in the shallow delta zone. Despite these intensive flocculation processes, a significant amount of SPM appears to remain in suspension and be transported offshore, as highlighted by the observed SPM concentrations which smoothly decrease from about 10 to $1 \mathrm{~g} \mathrm{~m}^{-3}$ as water salinity increases from 5 to about 25 (Fig. 10a). This phenomenon is apparently independent of the river outflow as observed on both west and east river transects.

A linear relationship $\left(R^{2}=0.83, N=19\right)$ is observed between the SPM concentration and water salinity, for salinity values ranging from 1 to 25 (Fig. 10b), in close agreement with previous observations (Emmerton et al., 2008). It suggests that mixing, thus dilution of the turbid freshwater, is the main process involved in the offshore transport of the SPM which did not rapidly settle down in the delta zone. Variations of water salinity in the delta zone also appear as a reasonably good $\left(R^{2}=0.83, N=10\right)$ indicator of the POC : SPM ratio, 

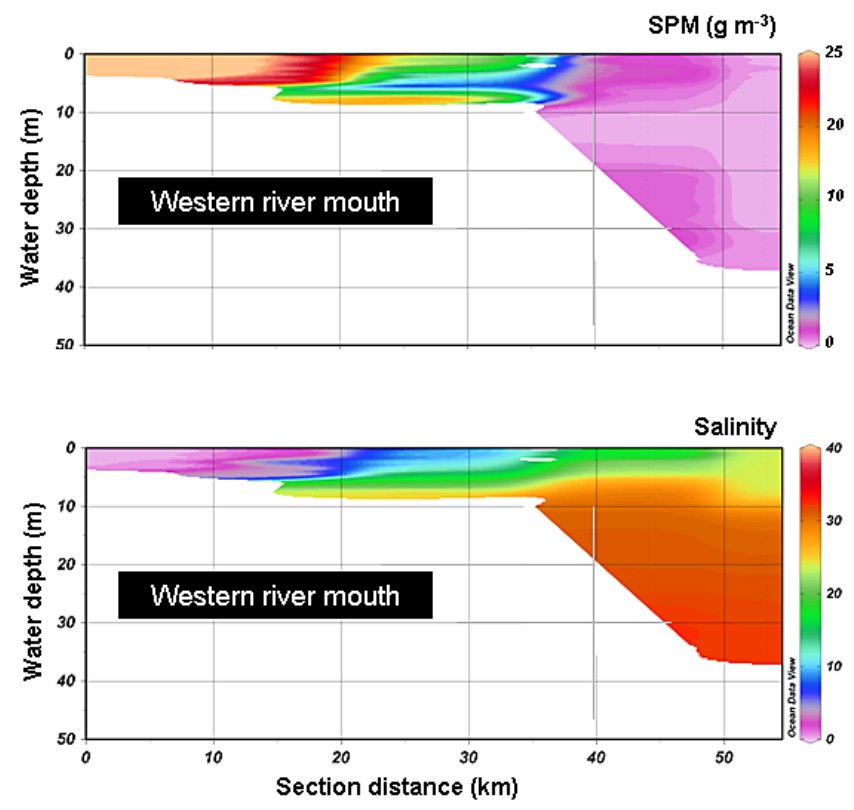

Fig. 8. Spatial variations of $b_{\mathrm{bp}}$ (715)-derived SPM concentration, in $\mathrm{g} \mathrm{m}^{-3}$ (see the text for details), and water salinity along the Mackenzie River mouth (west side). Measurements were carried out on the 13 August 2009.
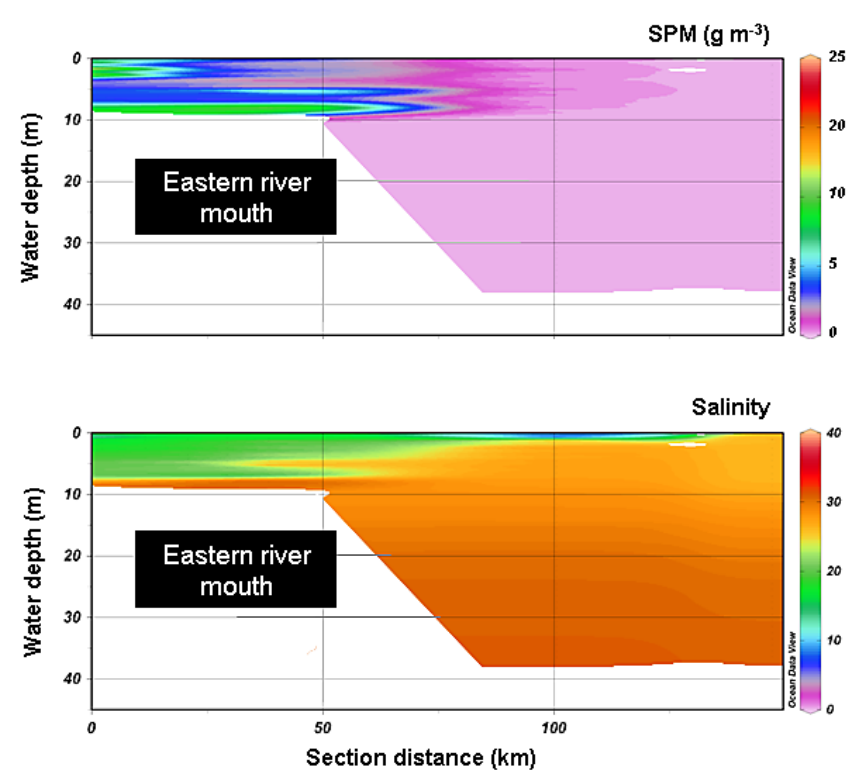

Fig. 9. Spatial variations of $b_{\mathrm{bp}}(715)$-derived SPM concentration, in $\mathrm{g} \mathrm{m}^{-3}$ (see the text for details), and water salinity along the Mackenzie River mouth (east side). Measurements were carried out on the 16 August 2009.

with ratio values close to $2 \%$ at the river mouth (salinity of 0 ) almost linearly increasing to values of about $10 \%$ for water salinities of 20 (Fig. 10c). Note that this relationship is obtained when combining the Malina dataset with previous measurements carried out in 2004 during the Canadian Arctic Shelf Exchange Study (Bélanger et al., 2008). Dilution seems to be the main process controlling the variations of the POC: SPM ratio from the river mouth up to a water salinity of 20 (see also Emmerton et al., 2008 for similar observations). Above this salinity value, suspended particles become phytoplankton-dominated with a POC : SPM ratio rapidly increasing up to $25 \%$ (Fig. 3).

Field measurements and satellite observations are qualitatively in agreement: both locate majority of the SPM on the west part of the river mouth, with a maximum turbidity zone confined in the river delta (water depth $<10 \mathrm{~m}$ ). The vertical homogeneity of water turbidity results from the high river outflow, as up to $80 \%$ of the Mackenzie freshwater discharge into the Beaufort Sea occurs through the west mouth. During the sampling period, the outflow through the east river mouth was too low to homogeneously maintain particles in suspension, so that stratification of turbidity rapidly occurred.

\subsection{Estimation of SPM and POC fluxes at the river mouth}

We finally attempt to estimate the fluxes of SPM and POC at the mouth of the Mackenzie River. For that we use (i) the freshwater discharge (monthly averages) measured by the Canadian Water Office, (ii) SPM concentrations retrieved from MODIS satellite data and (iii) POC: SPM ratio values documented based on field observations (river transects) during the Malina campaign. Estimations are therefore limited to the 2009, 2010 and 2011 summer periods (June to September). Available satellite observations are averaged within each month to produce monthly averages of SPM concentrations at the river mouth (i.e. within the pixels containing the two most upstream stations sampled along the river transects). It implies that the averaged SPM concentration obtained is more or less representative of the monthly averages depending on the number of satellite observations available. The SPM concentration retrieved from satellite data is assumed to be equal to the mean SPM concentration within the water column at the river mouth where water depths are respectively $2 \mathrm{~m}$ (west side) and $8 \mathrm{~m}$ (east side). This assumption is supported by our field optical measurements (see Figs. 8 and 9). The POC:SPM ratio at the river mouth is set to $2 \%$ based on our field dataset. According to previous studies in similar highly turbid estuarine waters (Doxaran et al., 2004, 2009), both bottom reflection and adjacency effects on $R_{\mathrm{rs}}$ retrieved from satellite data can be assumed to be negligible at 550 and $780 \mathrm{~nm}$, as a first approximation.

MODIS-Aqua satellite images providing cloud-free views of the whole Mackenzie River mouth were processed for the 2009, 2010 and 2011 summer periods. It allowed the estimation of the monthly-averaged SPM concentration in (i) July and August 2009 (3 and 2 MODIS-Aqua images, respectively), (ii) June, August and September 2010 (2, 1 and 2 images, respectively) and (iii) June, August and 
a

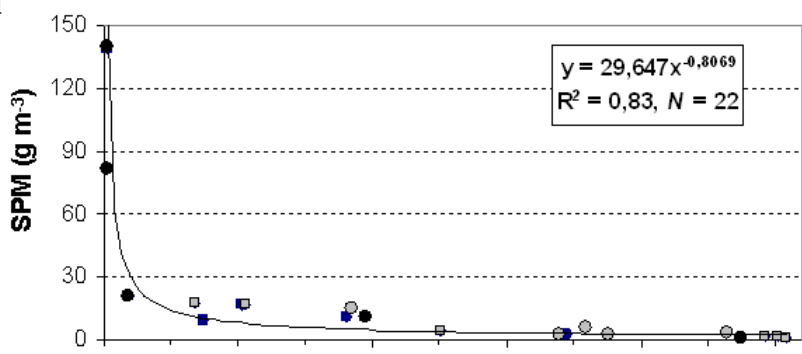

$b$

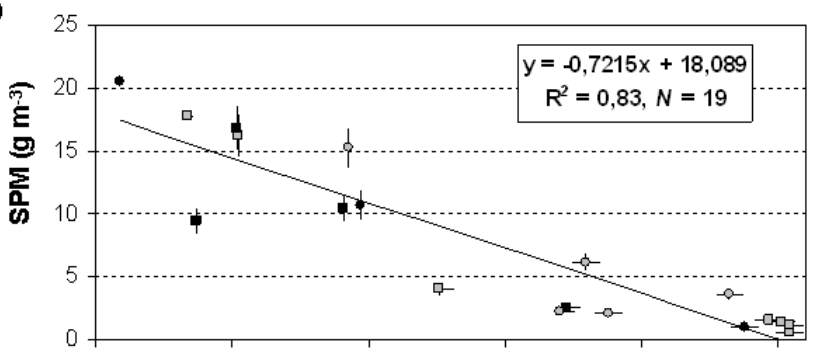

$\mathrm{C}$

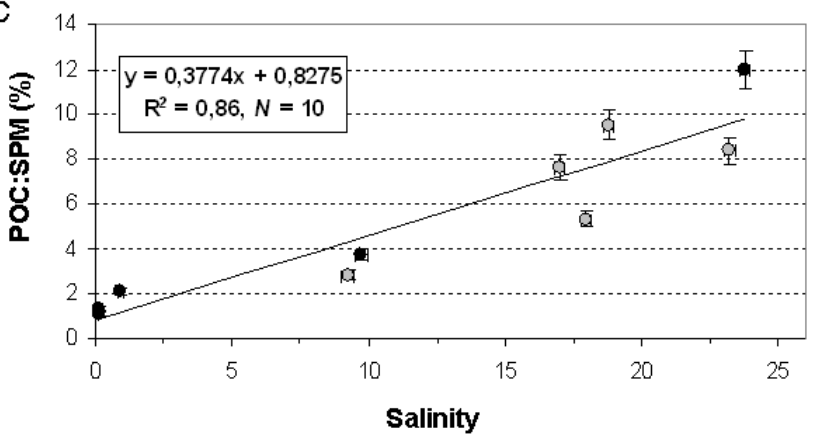

Fig. 10. Observed variations of the SPM concentration (a), SPM concentration (values lower than $25 \mathrm{~g} \mathrm{~m}^{-3}$ ) (b) and POC : SPM ratio (c) as a function of water salinity. Only stations along the two river transects where the water salinity, SPM and POC concentrations were measured simultaneously are reported. Black and grey circles respectively represent the west and east river transects. For comparison measurements of salinity and SPM concentrations carried out along the same river transects during the Canadian Arctic Shelf Exchange Study (CASES) in June and July 2004 (see Bélanger et al., 2008 for exact sampling locations) (black and grey squares, respectively for the west and east river transects) are included. The power-law (a) and linear (b) regressions between SPM and salinity were obtained when considering the Malina and CASES measurements.

September 2011 (3, 3 and 2 images, respectively). The resulting monthly-averaged SPM concentrations were: 245 and $145 \mathrm{~g} \mathrm{~m}^{-3}$ (2009), 315, 175 and $145 \mathrm{~g} \mathrm{~m}^{-3}$ (2010), 345, 145 and $130 \mathrm{~g} \mathrm{~m}^{-3}$ (2011). Taking into account the uncertainties associated with the estimated SPM concentration within the whole water column at the river mouth (say $\pm 25 \%$ ) (Doxaran et al., 2009), these values were multiplied by the volume (in $\mathrm{m}^{3}$ ) of freshwater discharged each month to obtain an estimation of the SPM fluxes: (i) $(18 \pm 4) \times 10^{12} \mathrm{~g}$ in July and August 2009, (ii) $(23 \pm 4) \times 10^{12} \mathrm{~g}$ in June, August and September 2010 and (iii) $(29 \pm 5) \times 10^{12} \mathrm{~g}$ in June, August and September 2011. Assuming a constant POC: SPM ratio of $2 \%$ at the river mouth during these periods, the corresponding POC fluxes are (i) $(0.4 \pm 0.2) \times 10^{12} \mathrm{~g}$ in July and August 2009; (ii) $(0.5 \pm 0.2) \times 10^{12} \mathrm{~g}$ in June, August and September 2010; and (iii) $(0.6 \pm 0.3) \times 10^{12} \mathrm{~g}$ in June, $\mathrm{Au}-$ gust and September 2011 (Table 1).

These monthly fluxes can be compared to previous rough estimates of SPM and POC delivered annually by the Mackenzie River to the delta: $127 \times 10^{12} \mathrm{~g}$ and $2 \times 10^{12} \mathrm{~g}$, respectively (Macdonald et al., 1998 and references therein). Our estimates are in the good order of magnitude but are lower than expected considering that most of the freshwater and SPM are discharged between May and September. Our SPM algorithm still requires a full validation based on match-ups with field measurements at the river mouth. Also the monthly-averaged SPM concentrations estimated from ocean colour remote sensing data depend on the number of available cloud-free satellite images; this number can significantly increase by using MERIS and MODIS-Terra satellite observations in addition to MODIS-Aqua. Third, the highest SPM concentrations at the Mackenzie River mouth are certainly found in May and June during the breaking-up of the stamukhi, periods during which few cloud-free satellite observations were available in 2009, 2010 and 2011. This may partly explain the rather low SPM fluxes estimated based on remote sensing data in the present study. Moreover, previous estimates were based on field measurements made in the Mackenzie River, i.e. upstream the river delta, while our remote sensing observations concerned the mouth of the Mackenzie River, i.e. the exact limit between the river and adjacent coastal waters. In order to estimate SPM fluxes exported to the ocean, field measurements carried out several $\mathrm{km}$ upstream the river mouth tend to underestimate the trapping of SPM within the delta zone (e.g. Seitzinger et al., 2005; Doxaran et al., 2009). The advantage of remote sensing data is their capability to estimate SPM concentrations exactly at the river mouth.

\section{Summary and conclusions}

This study first allowed documentation of the organic carbon content of particles in suspension in the Mackenzie River delta, turbid plume and adjacent Beaufort Sea waters during the summer 2009. The content was shown to vary from one extreme to another, i.e. from the mineral-rich particles at the river mouth (POC:SPM ratio of $2 \%$ on average) to organic-rich particles away from the river plume (POC : SPM ratio in the range $10-45 \%$ ). The river plume waters appeared as a complex transition zone with mixed mineral and organic particles and a POC: SPM ratio typically increasing with decreasing SPM concentration. Our results have highlighted the potential of combined field optical measurements and ocean colour satellite data to estimate SPM and POC 
Table 1. Monthly-averaged SPM concentration $\left(\mathrm{g} \mathrm{m}^{-3}\right)$ at the river mouth, based on MODIS-Aqua satellite observations, and corresponding monthly-averaged freshwater discharge $\left(\mathrm{m}^{3} \mathrm{~s}^{-1}\right)$. The monthly-averaged SPM flux $\left(\times 10^{12} \mathrm{~g}\right)$ at the river mouth is estimated as the product between the monthly-averaged SPM concentration and monthly freshwater discharge; the associated monthlyaveraged POC flux $\left(\times 10^{12} \mathrm{~g}\right)$ at the river mouth is estimated assuming a constant POC : SPM ratio of $2 \%$.

\begin{tabular}{lccrc}
\hline Period & $\begin{array}{c}\text { Mean SPM } \\
\text { concentration } \\
\mathrm{g} \mathrm{m}^{-3}\end{array}$ & $\begin{array}{c}\text { Mean freshwater } \\
\text { discharge } \\
\mathrm{m}^{-3} \mathrm{~s}^{-1}\end{array}$ & $\begin{array}{r}\text { SPM flux } \\
\left(\times 10^{12} \mathrm{~g}\right)\end{array}$ & $\begin{array}{c}\text { POC flux } \\
\left(\times 10^{12} \mathrm{~g}\right)\end{array}$ \\
\hline July 2009 & $250 \pm 50$ & 20200 & $13 \pm 3$ & $0.3 \pm 0.1$ \\
August 2009 & $150 \pm 30$ & 13300 & $5 \pm 2$ & $0.1 \pm 0.1$ \\
Total 2009 & - & - & $18 \pm 3$ & $0.4 \pm 0.2$ \\
June 2010 & $320 \pm 70$ & 14500 & $12 \pm 3$ & $0.2 \pm 0.1$ \\
August 2010 & $180 \pm 40$ & 12900 & $6 \pm 2$ & $0.1 \pm 0.1$ \\
September 2010 & $150 \pm 30$ & 12500 & $5 \pm 2$ & $0.1 \pm 0.1$ \\
Total 2010 & - & - & $23 \pm 3$ & $0.5 \pm 0.2$ \\
June 2010 & $350 \pm 70$ & 19970 & $18 \pm 3$ & $0.4 \pm 0.2$ \\
August 2010 & $150 \pm 30$ & 16483 & $6 \pm 2$ & $0.1 \pm 0.1$ \\
September 2010 & $130 \pm 30$ & 12483 & $4 \pm 2$ & $0.1 \pm 0.1$ \\
Total 2010 & - & - & $29 \pm 3$ & $0.6 \pm 0.3$ \\
\hline
\end{tabular}

concentrations at the Mackenzie River mouth and also within the river plume.

Regional proxies were identified to estimate SPM concentrations in the Mackenzie River delta and turbid plume from bio-optical measurements, namely based on the attenuation and particulate backscattering coefficients. Our results proved to be consistent with SPM-specific inherent optical properties typical of coastal waters (e.g. Babin et al., 2003b; Neukermans et al., 2012). Moreover, a robust quantification relationship was developed to estimate SPM concentrations from remote sensing reflectance $\left(R_{\mathrm{rs}}\right)$ measurements (i.e. either from field or atmospherically-corrected ocean colour satellite data). This relationship was established using a semi-analytical approach based on the measured SPM massspecific inherent optical properties then reproduced using a fully-empirical approach used to relate $R_{\mathrm{rs}}$ and SPM concentration field measurements. The results obtained are consistent with those previously obtained in sediment-dominated European estuaries (Doxaran et al., 2006). The regional relationship established in the Mackenzie River plume was proved to be robust but still potentially affected by variations in CDOM concentrations.

The application of this relationship to ocean colour satellite data requires the accurate retrieval of the $R_{\mathrm{rs}}$ signal in visible (around $560 \mathrm{~nm}$ ) and near-infrared (around $780 \mathrm{~nm}$ ) spectral bands. It was tested on a selection of cloud-free MODIS-Aqua satellite data recorded in 2009, 2010 and 2011. The near-infrared (two bands) atmospheric correction provided satisfactory results, in terms of $R_{\mathrm{rs}}$ retrieval, in the moderately turbid waters of the Mackenzie River plume. As a result, the surface SPM concentrations retrieved from MODIS data were within the expected range and allowed analysis of the seasonal to multi-annual dynamics of SPM.
A permanent maximum turbidity zone was identified in the river delta (up to the $10 \mathrm{~m}$ isobath), while the offshore extension of the plume (predominantly westwards or northwards) was observed to closely respond to variations in the Mackenzie freshwater discharge.

The location of the maximum turbidity zone in the river delta was confirmed by field measurements which also allowed detection of the presence of mineral-rich particles within surface waters of the Beaufort Sea, up to $300 \mathrm{~km}$ offshore. Moreover, SPM concentrations at the river mouth were observed to exhibit weak vertical variations along the water column, highlighting the potential of ocean colour remote sensing data to provide new estimates of SPM and POC fluxes exported by the Mackenzie River into the Beaufort Sea. The fluxes estimated in this study as part of a preliminary exercise proved to be in the good range but further work (i.e. field and satellite observations) is necessary to quantify the particulate fluxes during the spring (May-June) period.

Additional field measurements are required to assess the robustness of the optical proxies identified in this study, and the validity of the SPM quantification algorithm developed for ocean colour remote sensing. In an optimal scenario, insitu field data would be acquired coincidentally with satellite imagery (a so called match-up). The next step will be the routine application of the developed quantification algorithm to MODIS and MERIS satellite data recorded since 2002 for operational monitoring of the SPM and POC fluxes delivered by the Mackenzie and other major rivers to the Arctic Ocean.

Acknowledgements. This study was funded by ANR, the French Agence Nationale de la Recherche (Malina project, P. I. M. Babin), by the Centre National d'Etudes Spatiales (CNES-France) through the Provpanache project and by the Groupe Mission MERCATOR/CORIOLIS (France). We acknowledge the NASA GSFC for providing free access to MODIS satellite data and SeaDAS software, Environment Canada, namely the Water Office www.wateroffice.ec.gc.ca, for providing the daily water discharge of the Mackenzie River main tributaries. We finally thank two reviewers for their very useful comments and C. Neil for English review.

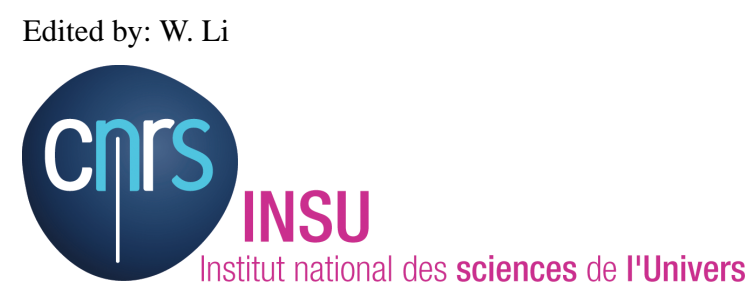

The publication of this article is financed by CNRS-INSU. 


\section{References}

Antoine, D., Morel, A., Leymarie, E., Houyou, A., Gentili, B., Victori, S., Buis, J.-P., Buis, N., Meunier, S., Canini, M., Crozel, D., Fougnie, B., and Henry, P.: Underwater radiance distributions measured with miniaturized multispectral radiance cameras, J. Atmos. Oceanic Technol., doi:10.1175/JTECH-D-1100215.1, 2012.

Babin, M., Stramski, D., Ferrari, G. M., Claustre, H., Bricaud, A., Obolensky, G., and Hoepffner, N.: Variations in the light absorption coefficients of phytoplankton, non-algal particles, and dissolved organic matter in coastal waters around Europe, J. Geophys. Res., 108, 3211-3230, doi:10.1029/2001JC000882, $2003 \mathrm{a}$.

Babin, M., Morel, A., Fournier-Sicre, V., Fell, F., and Stramski, D.: Light scattering properties of marine particles in coastal and oceanic waters as related to the particle mass concentration, Limnol. Oceanogr., 48, 843-859, 2003 b.

Babin, M. and Stramski, D.: Variations in the mass-specific absorption coefficient of mineral particles suspended in water, Limnol. Oceanogr., 49, 756-767, 2004.

Bélanger, S., Babin, M., and Larouche, P.: An empirical ocean color algorithm for estimating the contribution of chromophoric dissolved organic matter to total light absorption in optically complex waters, J. Geophys. Res., 113, C04027, doi:10.1029/2007JC004436, 2008.

Boss, E. and Pegau, W. S.: Relationship of light scattering at an angle in the backward direction to the backscattering coefficient, Appl. Optics, 40, 5503-5507, 2001.

Boss, E., Pegau, W. S., Gardner, W. D., Zaneveld, J. R. V., Barnard, A. H., Twardowski, M. S., Chang, G. C., and Dickey, T. D.: Spectral particulate attenuation and particulate size distribution in the boundary layer of a continental shelf, J. Geophys. Res., 106, 9509-9516, 2001.

Boss, E., Pegau, W. S., Lee, M., Twardowski, M., Shybanov, E., Korotaev, G., and Baratange, F.: Particulate backscattering ratio at LEO 15 and its use to study particle composition and distribution, J. Geophys. Res., 109, C01014, doi:10.1029/2002JC001514, 2004.

Bricaud, A. and Stramski, D.: Spectral absorption coefficients of living phytoplankton and nonalgal biogenous matter: A comparison between the Peru upwelling area and the Sargasso Sea, Limnol. Oceanogr., 35, 562-582, 1990.

Carmack, E. C. and Macdonald, W. R.: Oceanography of the Canadian Shelf of the Beaufort Sea: A Setting for Marine Life, Arctic, 55, 29-45, 2002.

Copin-Montégut, G.: Matière en suspension dans les eaux de mer: répartition, composition chimique, origine et e'volution, Laboratoire de Physique et Chimie Marines, Thesis, Université Pierre et Marie Curie, p. 173, 1980.

Doxaran, D., Froidefond, J. M., Lavender, S. J., and Castaing, P.: Spectral signature of highly turbid waters. Application with SPOT data to quantify suspended particulate matter concentrations, Remote Sens. Environ., 81, 149-161, 2002.

Doxaran, D., Froidefond, J. M., and Castaing, P.: Remote sensing reflectance of turbid sediment- dominated waters. Reduction of sediment type variations and changing illumination conditions effects using reflectance ratios, Appl. Optics, 42, 2623-2634, 2003.

Doxaran, D., Cherukuru, R. C. N., and Lavender, S. J.: Surface reflection effects on upwelling radiance field measurements in tur- bid waters, J. Opt. A-Pure Appl. Op., 6, 690-697, 2004.

Doxaran, D., Cherukuru, R. C. N., and Lavender, S. J.: Inherent and apparent optical properties of turbid estuarine waters: measurements, modelling and application to remote sensing, Appl. Optics, 45, 2310-2324, 2006.

Doxaran, D., Froidefond, J. M., Castaing, P., and Babin, M.: Dynamics of the turbidity maximum zone in a macrotidal estuary (the Gironde, France): Observations from field and MODIS satellite data, Estuar. Coast. Shelf Sc., 81, 321-332, 2009.

Emmerton, C. A., Lesack, L. F. W., and Vincent, W. F.: Nutrient and organic matter patterns across the Mackenzie River, estuary and shelf during the seasonal recession of sea-ice, J. Mar. Syst., 74, 741-755, 2008.

Estapa, M. L., Boss, E., Mayer, L. M., and Roesler, C. S.: Role of iron and organic carbon in mass-specific light absorption by particulate matter from Louisiana coastal waters, Limnol. Oceanogr., 57, 97-112, 2012.

Frey, K. E. and McClelland, J. W.: Impacts of permafrost degradation on arctic river biogeochemistry, Hydrol. Proces., 23, 169$182,2009$.

Gordon, H. R., Brown, O. B., and Jacobs, M. M.: Computed relations between the inherent and apparent optical properties of a flat homogeneous ocean, Appl. Optics, 14, 417-427, 1975.

Hedges, J. I., Keil, R. G., and Benner, R.: What happens to terrestrial organic matter in the ocean?, Org. Biogeochem., 27, 195212, 1997.

Hooker, S. B., Morrow, J. H., and Matsuoka, A.: The $1 \%$ and $1 \mathrm{~cm}$ perspective in deriving and validating AOP data products, Biogeosciences Discuss., 9, 9487-9531, doi:10.5194/bgd-9-94872012, 2012.

Kishino, M., Takahashi, M., Okami, N., and Ichimura, S.: Estimation of the spectral absorption coefficients of phytoplankton in the sea, B. Mar. Sci., 37, 634-642, 1985.

Kou, L., Labrie, D., and Chylek, P.: Refractive indices of water and ice in the 0.65- to 2.5- $\mu \mathrm{m}$ spectral range, Appl. Optics, 32, 35313540, 1993.

Langford, V. S., McKinley, A. J., and Quickenden, T. I.: Temperature dependence of the visible-near-infrared absorption spectrum of liquid water, J. Phys. Chem. A, 105, 8916-8921, 2001.

Loisel, H. and Morel, A.: Non-isotropy of the upward-radiance field in typical coastal case 2 waters, Int. J. Remote Sens., 22, 275295, 2001.

Macdonald, R. W., Paton, D. W., Carmack, E. C., and Omstedt, A.: The freshwater budget and under-ice spreading of Mackenzie River water in the Canadian Beaufort Sea based on salinity and ${ }^{18} \mathrm{O} /{ }^{16} \mathrm{O}$ measurements in water and ice, J. Geophys. Res., 100, 895-919, 1995.

Macdonald, R. W., Solomon, S. M., Cranston, R. E., Welch, H. E., Yunker, M. B., and Gobeil, C.: A sediment and organic carbon budget for the Canadian Beaufort shelf, Mar. Geol., 144, 255273, 1998.

Macdonald, R. W., McLaughlin, F. A., and Carmack, E. C.: Freshwater and its sources during the SHEBA drift in the Canada Basin of the Arctic Ocean, Deep-Sea Res., 49, 1769-1785, 2002. Matsuoka, A., Bricaud, A., Benner, R., Para, J., Sempéré, R., Prieur, L., Bélanger, S., and Babin, M.: Tracing the transport of colored dissolved organic matter in water masses of the Southern Beaufort Sea: relationship with hydrographic characteristics, Biogeosciences, 9, 925-940, doi:10.5194/bg-9-925-2012, 2012. 
McClelland, J. W., Holmes, R. M., Dunton, K. H., and Macdonald, R. W.: The Arctic Ocean Estuary, Estuar. Coasts, 35, 353-368, doi:10.1007/s12237-010-9357-3, 2012.

McKee, D., Chami, M., Brown, I., Calzado, V. S., Doxaran, D., and Cunningham, A.: Role of measurement uncertainties in observed variability in the spectral backscattering ratio: a case study in mineral-rich coastal waters, Appl. Optics, 48, 4663-4675, 2009.

Mobley, C. D.: Light and Water: Radiative Transfer in Natural Waters, Academic, San Diego, California, 1994.

Mobley, C. D.: Estimation of the remote-sensing reflectance from above-surface measurements, Appl. Optics, 38, 7442-7455, 1999.

Morel, A.: Optical properties of pure water and pure seawater, in: Optical aspects of oceanography, Academic Press, edited by: Jerlov, N. G. and Nielsen, E. S., 24 pp., 1974.

Morel, A. and Prieur, L.: Analysis of variations in ocean color, Limnol. Oceanogr., 22, 709-722, 1977.

Morrow, J. H., Booth, C. R., Lind, R. N., and Hooker, S. B.: "The Compact-Optical Profiling System (C-OPS)", in: 2010: Advances in Measuring the Apparent Optical Properties (AOPs) of Optically Complex Waters, edited by: Morrow, J. H., Hooker, S. B., Booth, C. R., Bernhard, G., Lind, R. N., and Brown, J. W., NASA Tech. Memo. 2010-215856, NASA Goddard Space Flight Center, Greenbelt, Maryland, 42-50 pp., 2010.

Nechad, B., Ruddick, K., and Park, Y.: Calibration and validation of a generic multisensor algorithm for mapping of total suspended matter in turbid waters, Remote Sens. Env., 114, 854-866, 2010.

Neukermans, G., Loisel, H., Mériaux, X., Astoreca, R., and McKee, D.: In situ variability of mass-specific beam attenuation and backscattering of marine particles with respect to particle size, density, and composition, Limnol. Oceanogr., 57, 124-144, 2012.

O’Brien, M. C., Macdonald, R. W., Melling, H., and Iseki, K.: Particle fluxes and geochemistry on the Canadian Beaufort shelf: implications for sediment transport and deposition, Cont. Shelf Res., 26, 41-81, 2006.

Park, Y. and Ruddick, K.: Model of remote-sensing reflectance including bidirectional effects for case 1 and case 2 waters, Appl. Optics, 44, 1236-1249, 2005.

Peterson, B. J. R., Holmes, M., McClelland, J. W., Vorosmarty, C. J., Lammers, R. B., Shiklomanov, A. I., Shiklomanov, I. A., and Rahmstorf, S.: Increasing river discharge to the Arctic Ocean, Science, 298, 2171-2173, 2002.

Rachold, V. H., Eicken, V. V., Gordeev, M. N., Grigoriev, H. W., Hubberten, A. P., Lisitzin, V., Shevchenko, P., and Schirmeister, L.: Modern terrigenous organic carbon input to the Artic Ocean, in: The organic carbon cycle in the Artic Ocean, edited by: Stein, R. and MacDonald, R. W., Springer, New York, 33-54, 2004.
Roesler, C. S.: Theoretical and experimental approaches to improve the accuracy of particulate absorption coefficients from the Quantitative Filter Technique, Limnol. Oceanogr., 43, 16491660, 1998.

Röttgers, R. and Gehnke, S.: Light absorption by natural aquatic particles in the near-infrared (700-900 nm) spectral region, Appl. Optics, 51, 1336-1351, 2012.

Schlunz, B. and Schneider, R. R.: Transport of terrestrial organic carbon to the oceans by rivers: re-estimating flux and burial rates, Int. J. Earth Sciences, 88, 599-606, 2000.

Seitzinger, S. P., Harrison, J. A., Dumont, E., Beusen, A. H. W., and Bouwman, A. F.: ources and delivery of carbon, nitrogen, and phosphorus to the coastal zone: An overview of Global Nutrient Export from Watersheds (NEWS) models and their application, Global Biogeochem. Cy., 19, GB4S01, doi:10.1029/2005GB002606, 2005.

Stumpf, R. P. and Pennock, J. R.: Calibration of a general optical equation for remote sensing of suspended sediments in a moderately turbid estuary, J. Geophys. Res., 94, 14363-14371, 1989.

Sullivan, J. M., Twardowski, M. S., Zaneveld, J. R. V., Moore, C. M., Barnard, A. H., Donaghay, P. L., and Rhoades, B.: Hyperspectral temperature and salt dependence of absorption by water and heavy water in the $450-750 \mathrm{~nm}$ spectral range, Appl. Optics, 45, 5294-5309, 2006.

Twardowski, M. S., Boss, E., Macdonald, J. B., Pegau, W. S., Barnard, A. H., and Zaneveld, J. R. V.: A model for estimating bulk refractive index from the optical backscattering ratio and the implications for understanding particle composition in case I and case II waters, J. Geophys. Res., 106, 14129-14142, doi:10.1029/2000JC000404, 2001.

Van Der Linde, D. W.: Protocol for determination of total suspended matter in oceans and coastal zones, JRC Technical Note I.98.182, 1998.

Van Raaphorst, W. and Malschaert, J. F. P.: Ammonium adsorption in superficial North Sea sediments, Cont. Shelf Res., 16, 14151435, 1996.

Wang, M. and Shi, W.: The NIR-SWIR combined atmospheric correction approach for MODIS ocean color data processing, Opt. Express, 15, 15722-15733, 2007.

Wetlabs ECO BB User's Guide, Revision AC, Wetlabs Inc., 2007.

Wetlabs Absorption and Attenuation Meter (ac-9) User's Guide, Revision S, Wetlabs Inc., 2008.

Yunker, M. B., Macdonald, R. W., Cretney, W. J., Fowler, B. R., and McLaughlin, F. A.: Alkane, terpene, and polycyclic aromatic hydrocarbon geochemistry of the Mackenzie River and shelf: riverine contributions to Beaufort Sea coastal sediments, Geochim. Cosmochim. Ac., 57, 3041-3061, 1993.

Zaneveld, J. R. V., Kitchen, J. C., and Moore, C.: The scattering error correction of reflecting-tube absorption meters, Ocean Optics XII. Soc. Photo-Optical Instrum. Eng. (SPIE), 44-55, 1994. 